\title{
¿A quién le importa Europa? \\ La UE en las elecciones generales españolas de 2011
}

\author{
Cristina Ares Castro-Conde \\ Universidad de Santiago de Compostela, España \\ cristina.ares@usc.es
}

Recibido: 19-01-2015

Aceptado: 05-11-2015

\section{Resumen}

Este artículo versa sobre el papel de la Unión Europea (UE) en las elecciones generales en España. Emplea los siguientes materiales: la base de datos del Manifesto Project, los programas de los partidos que obtuvieron representación en los comicios de 2011, así como, también para 2011, la transcripción del único debate televisado y las cuentas en la red social twitter de los candidatos a la Presidencia del Gobierno del Partido Popular y del Partido Socialista. La metodología empleada es el análisis de contenido. Los datos confirman las expectativas derivadas de la teoría de la importancia (saliency theory). Los partidos españoles han desenfatizado los asuntos de la UE, incluso en 2011, cuando medidas impulsadas por el gobierno anterior, incluida una reforma constitucional, fruto de decisiones adoptadas a escala europea, motivaron la convocatoria anticipada de elecciones. La evolución del énfasis y posición sobre la UE de los partidos españoles contrasta con los cambios observados en estas variables en otros Estados miembros como Francia o Italia. Los hallazgos de esta investigación tienen implicaciones desde el punto de vista de la legitimidad democrática de la UE en España.

Palabras clave: teoría de la importancia; propiedad de un asunto; análisis de contenido; programas electorales; elecciones generales de 2011; España.

\section{Who Cares about Europe? The EU in the 2011 Spanish General Elections}

\begin{abstract}
This article deals with the role of the EU as an issue in Spanish electoral competition from the accession of this country to the European Community in 1986, as well as the role of the different EU issues in the 2011 Spanish general election. For the analysis of the entire period 1986-2011, MARPOR's dataset is employed. Regarding the 2011 election, the raw programs of the parties that obtained representation in the Congreso de los Diputados, the only televised debate, and the twitter accounts of the two main parties' candidates for the Presidency of the Government were used. The methodology is content analysis. Empirical evidence confirms saliency theory's expectations. Spanish parties don't put emphasis on EU affairs, indeed in 2011, that was an early election called as a result of certain unpopular measures, including a constitutional reform, promoted by the former national government on the basis of EU decisions. The evolution of Spanish parties' EU salience and position differs from changes in these variables in other Member States such as France or Italy. These findings have implications concerning the EU's democratic legitimacy in Spain.
\end{abstract}

Key words: saliency theory; issue ownership; content analysis; electoral manifestos; 2011 general election; Spain. 


\section{Referencia normalizada}

Ares Castro-Conde, C. (2016): “¿A quién le importa Europa? La UE en las elecciones generales españolas de 2011”, Política y Sociedad, 53 (1), pp. 217-258.

Sumario: Introducción. 1. Método y marco teórico. 2. La UE como asunto en la competición partidaria en España. 3. Los asuntos de la UE en las elecciones generales de 2011. 4. Conclusiones. 5. Bibliografía. 6. Apéndice.

\section{Introducción}

Este artículo aborda la competición política en los Estados miembros como un aspecto relevante de la discusión sobre la legitimidad democrática del sistema político de la Unión Europea (UE), centrándose en el caso español. ${ }^{1}$

Con anterioridad a la Gran Recesión, la mayoría de los españoles, con variaciones temporales en los niveles de apoyo, asociadas a factores tanto contextuales como europeos, se posicionaba a favor de la pertenencia a la UE (Díaz Medrano, 1995, 2003 y 2007). Las actitudes de los españoles hacía la Unión respondían a sus expectativas de mejora económica y en el estatus internacional del país así como a rasgos propios del proceso de democratización tras el final de la dictadura franquista (Álvarez-Miranda, 1994 y 1996; Beneyto, 1999; Quintanilla, 2000). Se trataba de un sostén acrítico que

${ }^{1}$ Históricamente, el déficit democrático de la UE tenía una dimensión institucional y otra sociológica. La primera se relacionaba con la forma de investidura y la falta de rendición de cuentas (accountability) de la Comisión Europea, la opacidad de las reuniones del Consejo de la Unión, la debilidad del Parlamento Europeo y también de los partidos políticos a escala europea, y el vaciamiento de atribuciones de los Parlamentos estatales (centrales y regionales en los Estados miembros descentralizados políticamente o con regiones con competencias legislativas). La segunda dimensión tenía que ver con la ausencia de un demos europeo (una comunidad política a escala europea con una identidad colectiva), y asimismo de una esfera pública común. Pero, la democratización de la UE desde Maastricht (1993) y sobre todo a partir de la entrada en vigor del Tratado de Lisboa (diciembre de 2009) ha sido notable. El Parlamento Europeo es hoy una institución fuerte: bajo el procedimiento legislativo ordinario, que se aplica para la mayor parte de los asuntos, co-legisla en pie de igualdad con el Consejo de la Unión; ha ganado poder también como autoridad presupuestaria; el nombramiento del Presidente de la Comisión está condicionado por el resultado de los comicios europeos y su elección corresponde al Parlamento Europeo. Al mismo tiempo, se ha garantizado la trasparencia de las reuniones del Consejo de la Unión cuando actúa como cámara legislativa. Además, se ha constitucionalizado y desarrollado legislativamente la iniciativa ciudadana. El Tratado de Lisboa ha empoderado también a los Parlamentos nacionales. Desde el punto de vista sociológico, incluso, la propia crisis del euro ha generado una embrionaria esfera pública europea. Sin embargo, entendiendo por democracia, igualdad política y capacidad ciudadana de influencia y control sobre las decisiones públicas, es cierto que la UE sigue teniendo a día de hoy, a pesar de las mejoras institucionales introducidas y la emergencia de un espacio público a escala europea, un problema de legitimidad democrática. 
no discriminaba "entre apoyo a la integración europea y apoyo a tipos concretos de integración" (Díaz Medrano, 2007: 230). En buena parte, se debía "a que para la inmensa mayoría de los españoles la democracia es precisamente el nexo de unión entre identidad nacional e identidad europea" (Torreblanca, 2014: 28). Y contenía "un elemento de irracionalidad a largo plazo no desdeñable" (Díaz Medrano, 2007: 230).² Antes de la crisis que se inició en 2007, Díaz Medrano advertía que "la falta de debate en el espacio público español sobre las virtudes y defectos de distintos modelos de integración y la reducción de la discusión pública a la distinción maniquea entres estar "a favor" o "en contra" de Europa puede estar contribuyendo a la irracionalidad a largo plazo de los españoles" (2007: 231).

A pesar de que en España nunca antes se había cuestionado el carácter positivo para la democracia de la integración europea (Fernández-Albertos, 2012; Morata, 1996 y 1999: 406-7; Rodríguez-Aguilera, 2008; Sánchez-Cuenca, 1999: 99 y 2014; Torreblanca, 2014), la crisis del euro despertó también en este país la preocupación por el déficit democrático de la Unión. De hecho, entre 2007 y 2012, España fue el Estado miembro que registró una mayor caída de apoyo a la UE: de 45 puntos (del 65\% al 20\%); la media de descenso de la confianza en la Unión durante estos años fue de 26 puntos: del 57\% al 31\% (Alonso, 2013; Jurado, 2013).

Las elecciones al Parlamento Europeo y los referenda europeos celebrados en este país han sido abundantemente estudiados (Aldecoa, 1994; Anduiza y Méndez, 2001; Closa, 2004; Fernández, 2006; Martínez y Méndez, 1999; Piedrafita, 2013; RodríguezAguilera, 2007; Torcal y Font, 2012; Torcal y Muñoz, 2012). Las prioridades de los gobiernos del PSOE y del PP en el ejercicio por parte de España de la presidencia semestral del Consejo de la Unión, han sido también ya objeto de examen (Barbé, 1999, 2003 y 2010; Fernández, 2007; Morata y Fernández, 2003; Sorroza y Molina, 2010). ${ }^{3}$ Sin embargo, el lugar de los asuntos de la UE en las elecciones generales

${ }^{2}$ Sobre las actitudes hacia la UE de los españoles, véase: Barreiro y Sánchez-Cuenca (2001), y Llamazares y Sandell (2001). Acerca de sus efectos en los partidos políticos en España, además de Llamazares y Sandell (2001), consúltese: Román (2001). Sobre “europeización" Héritier et al., (2001); Hix y Goetz, (2000); Radaelli, (2006); Vink y Graziano, (2007) de los partidos en general, constituyen referencias fundamentales: Aylott et al., (2007); Carter et al., (2007); Ladrech, (2002 y 2007); Mair, (2000 y 2007); Ramiro y Morales, (2007); Raunio, (2007). Acerca del efecto de la integración monetaria en la competición electoral, véanse: Menéndez (2012) y Urquizu (2012).

${ }^{3}$ Este país ha detentado la presidencia rotatoria en cuatro ocasiones: primer semestre de 1989 y segundo de 1995 (gobiernos presididos por Felipe González, PSOE), primer semestre de 2002 (segunda legislatura de José María Aznar, PP), y primero de 2010 (segunda de José Luis Rodríguez Zapatero, PSOE). En línea con los resultados de esta investigación, en lo que se refiere a las prioridades no dadas por la agenda política europea (como temas relativos a la unión monetaria, la respuesta a la Gran Recesión, reformas institucionales y adhesiones previstas) podemos hablar de continuidad en las presidencias españolas. Todas ellas han puesto el foco en asuntos de política exterior: la Agenda Transatlántica, particularmente las relaciones con América Latina, y la cooperación en el Mediterráneo. Si bien, más allá de estos temas coincidentes, las presidencias de 1989 y 2010 (PSOE) enfatizaron asuntos sociales, como la 
permanece inexplorado, a pesar, primero de todo, del importante papel del Presidente y en general del Gobierno central en la toma de decisiones a escala supranacional, o del emergente rol del Parlamento nacional a escala europea, cuya composición en ambos casos depende del resultado de estos comicios. ${ }^{4}$

Esta investigación trata de cubrir esta laguna, examinando la evolución de la importancia de la CE/UE como tema y las posiciones partidarias sobre la CE/UE a lo largo de los 30 primeros años de integración europea de España, y analizando en profundidad las propuestas sobre los diferentes asuntos de la Unión de las elecciones generales de $2011 .{ }^{5}$

¿El cambio en las actitudes de los españoles hacia la UE está relacionado con una mayor importancia de la Unión como tema en la competición política en este país? ¿Cómo de diferenciada es la oferta de las fuerzas políticas españolas en asuntos de la Unión?

La exposición de la investigación se estructurará del siguiente modo: en el apartado segundo, presentaremos el método y marco teórico; el tercero examinará el papel de la UE como tema en la competición electoral en España; en el cuarto, analizaremos el lugar de los distintos asuntos de la UE en la campaña de los comicios de 2011; finalmente, ofreceremos las conclusiones y la bibliografía, además de un breve apéndice con información complementaria relativa al ejercicio de codificación de los programas de las elecciones de 2011.

presentación de la carta social europea (1989, F. González) o la protección de las víctimas de violencia de género (2010, J.L. Rodríguez Zapatero). Mientras, la tercera presidencia, única ejercida con un gobierno del PP (J.M. Aznar), dio también importancia a temas de política interior, como la cooperación en la lucha contra el terrorismo o la inmigración ilegal (Barbé, 1999, 2003 y 2010; Euractiv, 2010; Fernández, 2007; López Garrido, 2010; Morata y Fernández, 2003; Sorroza y Molina, 2010).

${ }^{4}$ Por otra parte, sobre la incidencia de la UE en el poder ejecutivo español, véase: Molina (2001); y acerca de sus efectos en el poder legislativo, léase: Piedrafita (2014).

5 Se recomienda el trabajo de Nanou y Dorussen (2013) sobre la incidencia del proceso de integración europea en la competición partidaria en los Estados miembros; y de Stevens (2013) sobre la evolución de la UE como asunto en el Reino Unido. Acerca de los efectos de la diferenciación de la oferta partidaria en la satisfacción ciudadana, léase Ezrow y Xezonakis (2011). Para saber más, en general, sobre la competición electoral en España, véanse: Anduiza et. al (2010), Cordero y Martín (2011), y Martínez i Coma (2008). Los interesados en el análisis de las elecciones españolas de 2011, más allá de los temas relativos a la UE, pueden consultar: Martín y Urquizu-Sancho (2012) y Sánchez-Cuenca y Dinas (2012). 


\section{Método y marco teórico}

\subsection{Método}

El método usado es el análisis de contenido de textos políticos. ${ }^{6}$ La frase-núcleo, una serie de palabras que contienen un único argumento, es la unidad de análisis. ${ }^{7}$ En el procedimiento de descomposición de textos en cuasi-frases ${ }^{8}$ y para su codificación, aplicamos las reglas del Manifesto Project on Political Representation (Manifesto Project o MARPOR). ${ }^{9}$

En primer lugar, para el estudio del papel de la UE como tema en todas las elecciones generales celebradas desde 1986 empleamos la base de datos de MARPOR. ${ }^{10}$ Este proyecto, a partir del análisis de contenido de los programas electorales, ofrece medidas de la posición partidaria sobre la UE tratada como un único asunto. El esquema del Manifesto Project para la clasificación de preferencias programáticas sobre el sistema político, política y políticas distingue 56 categorías, que clasifica en 7 áreas de actuación gubernamental. Dos de las categorías clasificadas en el área Relaciones internacionales, "CE/UE: positivo" y "CE/UE: negativo", tienen que ver con la UE. Empleando conjuntamente las dos categorías podemos calcular tanto la posición combinada con relevancia como la posición pura de cada partido en cada elección.

En segundo lugar, a fin de examinar los comicios de 2011, usamos directamente los textos de los programas, $\mathrm{y}$, por si aportasen algún dato adicional sobre el lugar de los asuntos de la UE en esta campaña, la información política difundida a través del debate televisado y las cuentas en la red social twitter de los candidatos a la Presidencia del Gobierno del Partido Popular (PP) y del Partido Socialista (PSOE), únicos con opciones reales de encabezar el Gobierno de España en 2011. Codificamos con una clasificación

${ }^{6}$ Krippendorff define el análisis de contenido como "[Una] técnica de investigación para formular inferencias válidas y reproducibles a partir de ciertos textos (u otro material con significado) en los contextos de su uso" (2004:18). El análisis de contenido se distingue de la interpretación de textos en la vida cotidiana por su fiabilidad y validez (Alonso et al., 2012b: 14).

${ }^{7}$ Una frase-núcleo es una frase o parte de una frase (cuasi-frase) que expresa un argumento general único. Es necesario usarla como unidad de codificación en detrimento de la palabra aislada (o símbolo) cuando la investigación no se interesa únicamente por la frecuencia de aparición de ciertos términos en los textos, sino sobre todo por las posiciones mantenidas por un agente respecto a un asunto y su justificación.

${ }^{8}$ El criterio para dividir el texto en cuasi-frases es el siguiente: si una frase contiene un único argumento completo, no se divide; si contiene más de un argumento, se divide en tantas cuasi-frases como argumentos. Cada cuasi-frase debe contener un único argumento completo.

${ }^{9}$ Estas reglas pueden consultarse en: http://manifestoproject.wzb.eu.

10 Accesible en: https://manifestoproject.wzb.eu/elections/206 [Budge et al. (2001), Klingemann et al. (2006) y Volkens et al. (2012)]. Sobre la metodología de MARPOR, véase: Alonso et al. (2012), Budge et al. (2001), Klingemann et al. (2006) y Volkens et al. (2012, 2013, 2014, 2015b y 2015c). 
propia los programas de las fuerzas políticas que obtuvieron representación este año. ${ }^{11}$ Tomamos la decisión de realizar este segundo ejercicio de codificación de los programas de 2011 porque, si bien los datos de MARPOR nos bastan para el tratamiento de la UE como un único asunto, nuestro esquema nos resulta más útil para examinar las propuestas de los partidos en cada uno de los asuntos de la Unión a los que han prestado atención en estos comicios.

No obstante, queremos recordar que los proyectos Regional Manifestos Project (RMP, http://www.regionalmanifestosproject.com/espaol/que-es-el-rmp) y Euromanifesto Project (EM, http://eeshomepage.net/euromanifesto-study/), añadiendo a los códigos de la clasificación original del Manifesto Project dígitos sobre el nivel de toma decisiones y subcategorías específicas para los distintos niveles, han dado respuestas satisfactorias a la necesidad de dejar de tratar a la UE como un único tema para analizar los diversos asuntos de la Unión. ${ }^{12}$

La nueva clasificación se elaboró de forma inductiva, en el ejercicio de codificación de los programas de las elecciones generales de 2011, partiendo de un esquema deductivo preliminar, que sufrió notables variaciones a la vista de la información contenida en los textos examinados. El esquema, que se encuentra en el apéndice de este artículo (tabla 8), contiene un total de 29 categorías y distingue tres dimensiones del concepto "Unión Europea": proceso de integración europea, sistema político y políticas públicas de la UE, por lo que se estructura en tres áreas (Proceso de integración, Instituciones y actores, y Políticas Públicas). Creemos que estas 3 áreas permiten abordar distintos niveles de análisis de forma sencilla, y podrían tomarse en consideración en futuras investigaciones sobre el papel de los asuntos de la UE en la competición electoral.

En nuestro ejercicio de codificación para las elecciones de 2011 solo consideramos las cuasi-frases (de los programas, la transcripción del debate televisado y los tweets) que contienen una propuesta sobre un asunto de la UE. Por tanto, no codificamos las unidades de análisis que no contienen ninguna medida, aunque expresen un posicionamiento sobre un tema europeo $^{13}$ ni las propuestas que versan sobre la

${ }^{11}$ Con la excepción de Amaiur, cuyo programa, de acuerdo con los datos de MARPOR no contiene ninguna referencia al asunto UE. Los partidos que obtuvieron representación en el Congreso de los Diputados (porcentaje de voto y número de escaños) son: Partido Popular (PP, 45,24\%, 163); Partido Socialista (PSOE, 29,3\%, 110); Convergéncia i Unió (CiU, 4,24\%, 16); Izquierda Unida (IU, 7,02\%, 11); Amaiur (1,39\%, 7); Partido Nacionalista Vasco/Eusko Alderdi Jeltzalea (PNV/EAJ, 1,35\%, 5); Unión Progreso y Democracia (UPyD, 4,76\%, 5), Esquerra Republicana de Catalunya (ERC, 1.07\%, 3); Bloque Nacionalista Galego (BNG, 0,77\%, 2); Coalición Canaria (CC, $0,6 \%, 2)$; Compromís-Q $(0,52 \%, 1)$; Foro Asturias $(0,41 \%, 1)$; y Geroa Bai $(0,18 \%, 1)$.

12 Resulta muy recomendable la lectura de Alonso et al. (2013) para conocer el esquema alternativo del Regional Manifestos Project, aplicable al examen de la competición electoral en cualquier sistema político multinivel.

${ }^{13}$ Ejemplos de párrafos que contienen un posicionamiento sobre un asunto europeo, pero no una propuesta, y por tanto no se examinan en este trabajo: "La redefinición de las políticas agrarias y pesqueras en la Unión Europea nos ofrece una magnífica oportunidad, más equitativa 
adaptación a la pertenencia a la UE del sistema político español. ${ }^{14}$ Para la asignación de las propuestas a una de las 29 categorías, aplicamos, como MARPOR, las reglas del manual de codificación de Volkens (2002), entre las que destacamos, por la particular utilidad demostrada en este ejercicio de codificación, las dos siguientes. Las categorías del área Políticas públicas (objetivos) tienen preferencia sobre las categorías del área Instituciones y actores (medios). Las categorías más específicas tienen prioridad sobre las más generales (por ejemplo, en el área Proceso de integración, la categoría Democratización tiene preferencia sobre la categoría Profundización).

\subsection{Marco teórico}

En contra de la teoría espacial de la competición partidaria (Downs, 1957) y de acuerdo con la teoría de la importancia (saliency theory) (Budge et al. 1987: 24-8; Budge et al., 2001; Dolezal et al., 2014), asumimos que los partidos no compiten ofreciendo respuestas (posiciones) diferenciadas a los problemas (asuntos) de una agenda política dada sino tomando decisiones sobre qué asuntos de su particular "cartera" ideológica (des)enfatizar.

La teoría de la importancia asume que la estrategia partidaria más frecuente es el "énfasis selectivo", en lugar de la "confrontación directa" (Budge y Farlie, 1983). Espera que los partidos como actores racionales enfaticen desproporcionadamente aquellos asuntos que consideran de su "propiedad" (issue ownership) porque los votantes perciben al partido como más competente que sus oponentes en estos temas (Budge, 1982: 149). Aguarda también que las fuerzas políticas desenfaticen aquellos

socialmente hablando, dado que son las pequeñas explotaciones agrarias, muchas de ellas en espacios Red Natura, las que salen beneficiadas de una PAC más verde, que reconozca los beneficios que aporta a la comunidad su preservación y custodia" (Programa PSOE: pág. 30); o "En los últimos años son varios los síntomas de colapso del modelo, en medio de una crisis económica y política que golpea a la clase trabajadora y supone un vaciamiento de la democracia representativa al evidenciarse que las decisiones clave las adoptan las grandes fortunas, capaces de hundir o reflotar una moneda, y organismos europeos y mundiales que no responden a ninguna legitimación democrática" (Programa IU: pág. 25); o "La identidad y gobernanza europeas no son contrarias a la identidad y gobernanza vascas. Todo lo contrario" (Programa PNV: pág. 31)

14 Ejemplos de párrafos que tampoco se analizan porque se refieren a decisiones que se adoptan en el nivel estatal y no en el supranacional: "Impulsaremos las medidas que nos permitan cumplir el compromiso, en el seno de la Unión Europea, del 20-20-20 en el año 2020" (Programa PP: pág. 13); o "Promoveremos el aumento de las dotaciones estatales a los programas de movilidad de estudiantes, muy especialmente el programa Erasmus, a fin de que puedan cubrir los gastos de desplazamiento y manutención de los estudiantes en las universidades de destino, de una manera digna" o "Garantizar a Cataluña la circunscripción electoral propia en las elecciones al Parlamento Europeo" (Programa CiU: págs. 85 y 108 respectivamente); o "Exigimos un desarrollo temporal (de los Corredores Atlántico y Mediterráneo) ajustado a las previsiones y exigencias europeas" (Programa PNV: pág. 21); o "Reforzar la unidad de la acción española en Europa, reformando la Comisión Mixta Congreso-Senado para la UE” (Programa UPyD: pág. 45). 
asuntos sobre los que perciben su posición como electoralmente desventajosa, al considerarlos propios de otros partidos o por la distancia entre su posición partidaria y las preferencias de la mayoría de los votantes sobre el tema.

Por tratarse de un asunto que no es propiedad de ningún partido en España, aplicando la teoría de la importancia, esperamos que las fuerzas políticas en este país compitan desenfatizando la UE como tema y no mediante la confrontación directa sobre asuntos de la Unión. De la combinación de estas estrategias resultará poca diferenciación en la oferta partidaria sobre temas de la UE.

\section{La UE como asunto en la competición electoral en España}

En este apartado, como hemos adelantado, empleando las medidas de MARPOR de énfasis y posición sobre la CE/UE de los partidos con representación parlamentaria a nivel estatal, analizaremos el papel de la UE como asunto en la competición partidaria en las elecciones generales. Estudiaremos la evolución en España de cada una de estas variables tanto a nivel agregado como para los distintos partidos. También, valoraremos las tendencias en perspectiva comparada con otros países de nuestro entorno.

\section{1. Énfasis sobre la UE en la competición electoral en España}

En el gráfico 1, que representa la evolución del énfasis sobre la UE, resultado de la suma de las frases codificadas en las categorías 108 y 110, de los partidos españoles que obtuvieron representación en al menos dos de las ocho elecciones generales de 1986, 1989, 1993, 1996, 2000, 2004, 2008 y 2011, observamos cómo el porcentaje de frases dedicadas a la CE/UE es bajo en todos los comicios. Las elecciones en las que los partidos dedicaron más atención a la Unión en sus programas fueron las de 1996 (5,21\%), y las que menos, las de 2004 (1,74\%). El dato de 2011 es el segundo peor $(2,00 \%)$.

No se aprecia relación entre el lugar de la CE/UE en la competición partidaria en España y la evolución del proceso de integración europea. La atención sobre este tema solo aumenta en el momento inmediatamente posterior a la entrada en vigor del Tratado de Maastricht (1993). La importancia se reduce tanto en el cambio de siglo con el inicio de la integración monetaria en la eurozona, como en pleno debate sobre el Tratado por el que se establece una Constitución para Europa (2004), al igual que cuando entra en vigor del Tratado de Lisboa (2009).

Nos llama especialmente la atención el descenso de la importancia de la UE de 2008 a 2011, dados los efectos sobre la política española de las decisiones adoptadas a escala europea durante la Gran Recesión. Los propios comicios de 2011 fueron adelantados a causa de la impopularidad de medidas adoptadas por el gobierno presidido por José Luis Rodríguez Zapatero, quien promovió una reforma constitucional en agosto de ese año para incorporar el freno automático al déficit público y la garantía de la prioridad del pago de la deuda en los presupuestos nacionales, obligación establecida en el 
Tratado de Estabilidad, Coordinación y Gobernanza, que no entraría en vigor hasta el 1 de enero de 2013. ${ }^{15}$

Gráfico 1: Evolución del énfasis sobre la UE (todos los partidos con representación parlamentaria)

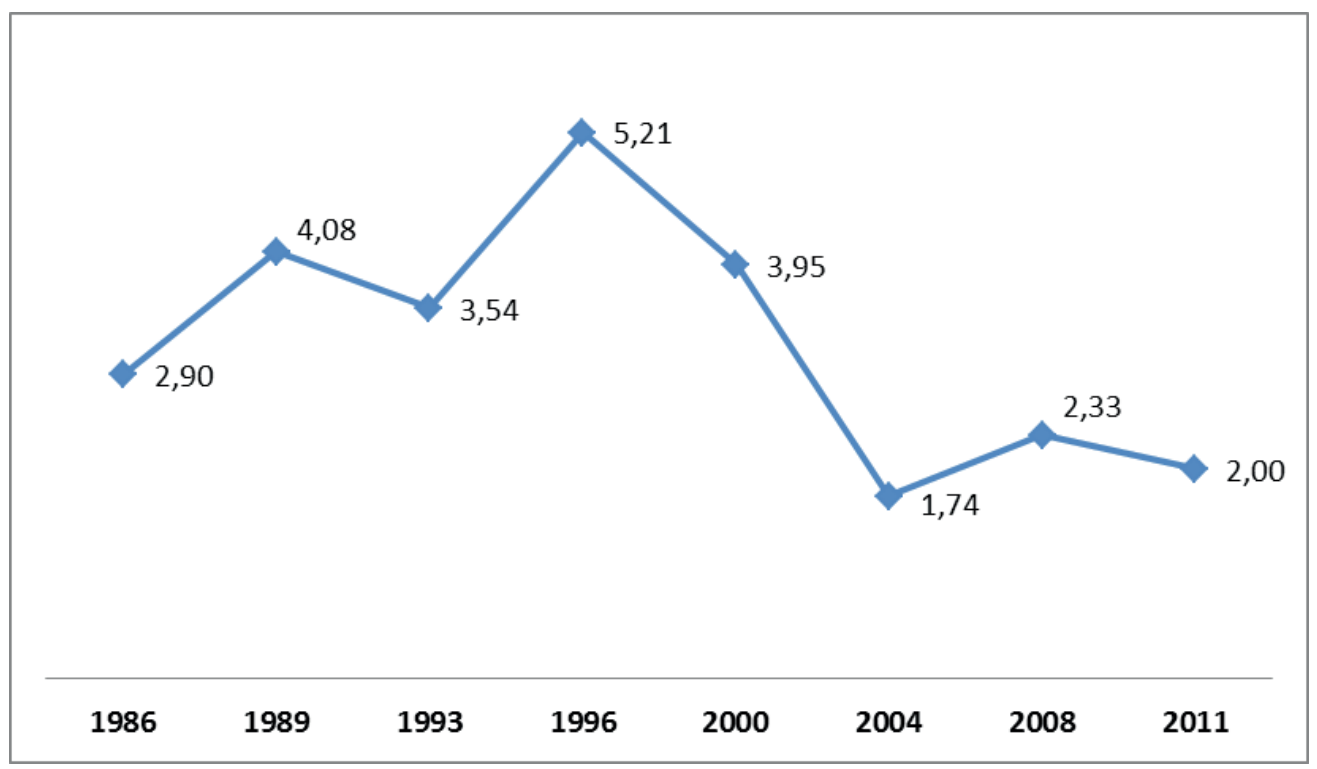

Fuente: Elaboración propia, empleando datos del Manifesto Project, accesibles en: https://manifestoproject.wzb.eu/elections/206 [Budge et al. (2001), Klingemann et al. (2006) y Volkens et al. (2012)].

El gráfico 2, en cuyo eje de abscisas se halla la variable importancia del tema UE y en el de ordenadas la variable posición sobre la Unión, muestra cómo solo BNG, PNV y PP prestan más atención a la UE en las elecciones de 2011 que en las anteriores de 2008.

${ }^{15}$ Véase Closa (2014), quien además de dar cuenta de la génesis y contenido de las nuevas reglas macroeconómicas y fiscales europeas, detalla cómo solo una minoría de Estados miembros han cumplido con la obligación de constitucionalizar el freno automático para el déficit público y la garantía de prioridad del pago de la deuda, contenida en el Pacto Fiscal (págs. 79-80). 
Gráfico 2: Cambios en el énfasis sobre la UE de los partidos españoles entre 2008 y 2011

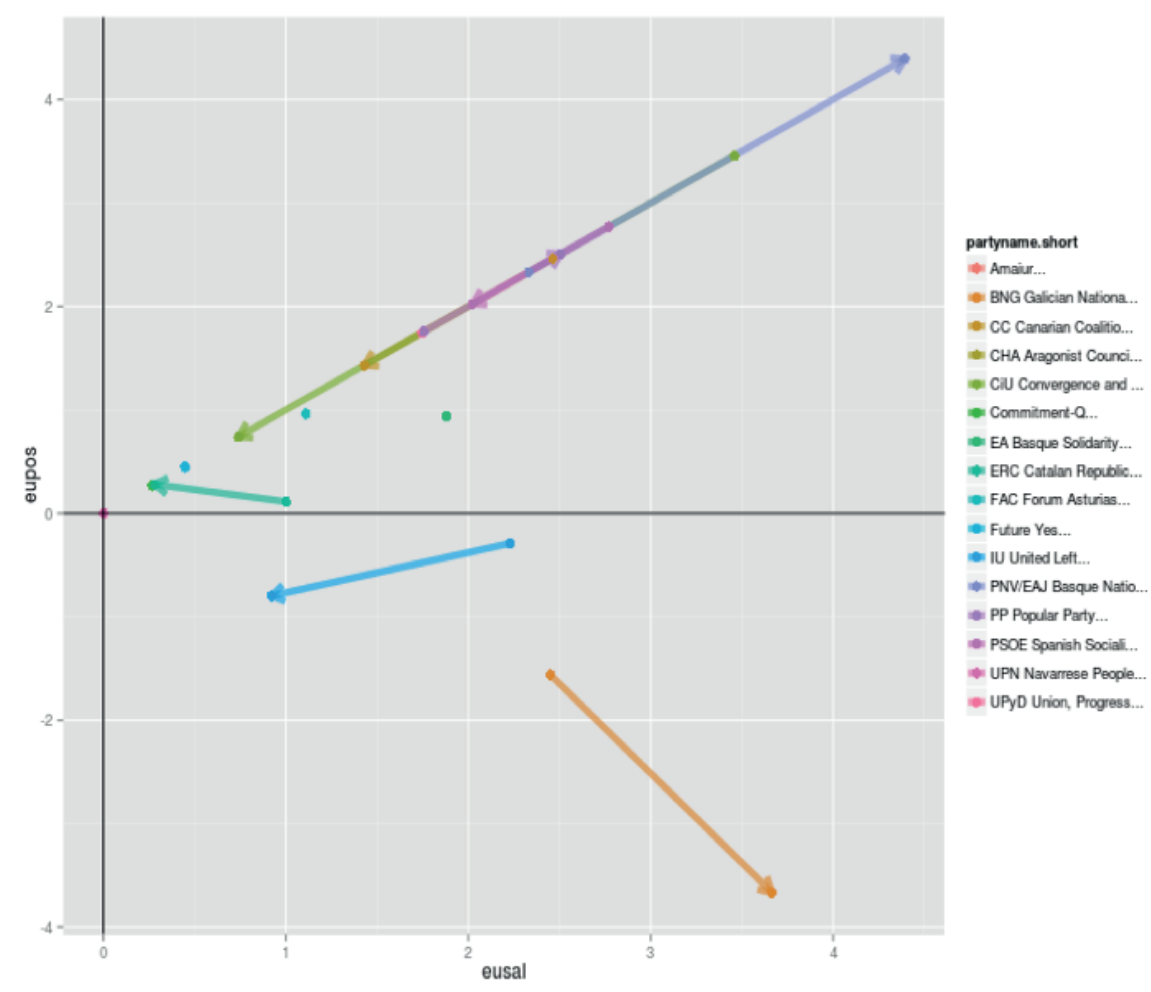

Fuente: Volkens, A. / Lehmann, Pola / Matthieß, Theres / Merz, Nicolas / Regel, Sven / Werner, Annika (2015): Manifesto Corpus. Versión: 2015a. Berlín: WZB.

\subsection{Posición agregada sobre la UE de las fuerzas políticas españolas}

En el gráfico 3 se emplea la posición media de las fuerzas políticas que obtuvieron representación en cada una de las elecciones generales para ilustrar la evolución de la posición de los partidos españoles sobre la CE/UE.

Se observa también una clara tendencia descendente en la posición de los partidos españoles a favor de la UE. ${ }^{16}$ La posición media de las fuerzas políticas con representación en el Congreso de los Diputados alcanzó su máximo en las elecciones de 1989 (5,2), y no ha dejado de descender desde entonces, hasta el 0,9 de las elecciones de 2011.

${ }^{16}$ Sobre posicionamientos euroescépticos en los partidos españoles, consúltese: Llamazares, Gómez-Reino y Ramiro-Fernández (2008). 
Gráfico 3: Evolución de la posición sobre la UE

(todos los partidos con representación parlamentaria)

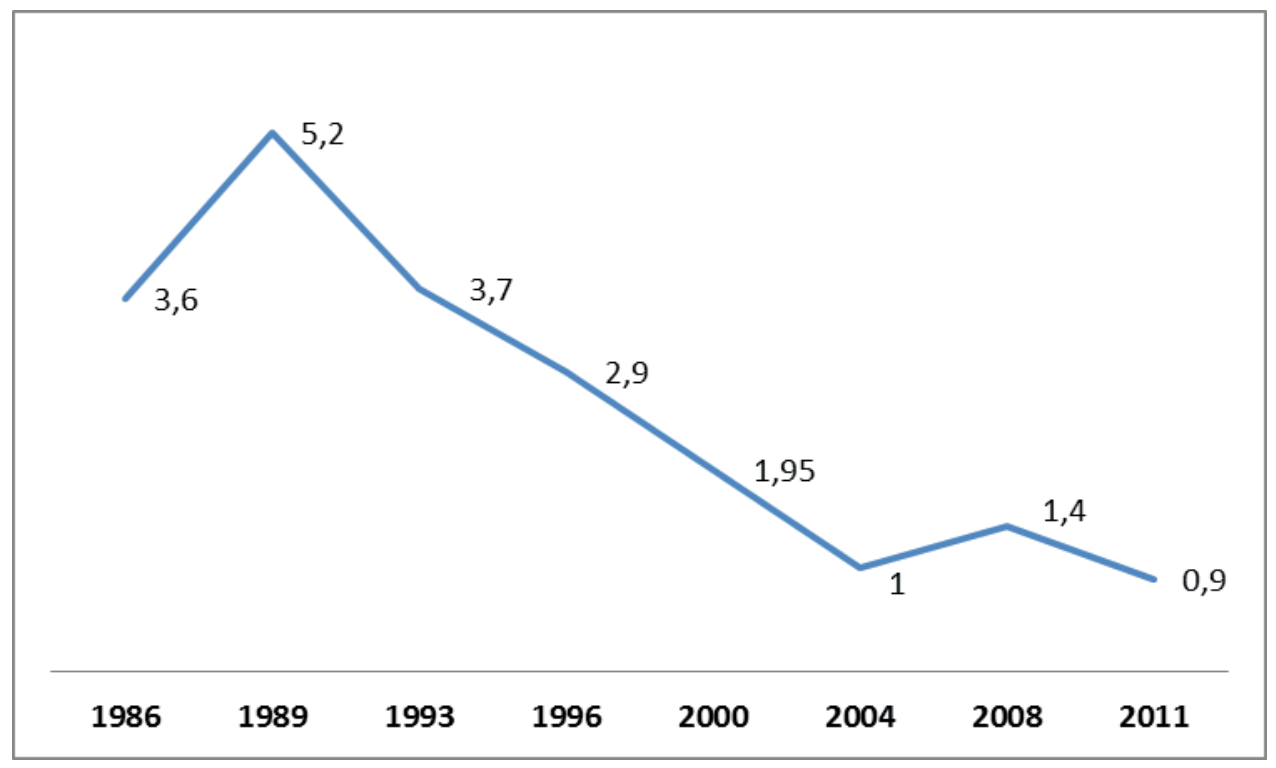

Fuente: Elaboración propia, empleando datos del Manifesto Project, accesibles en: https://manifestoproject.wzb.eu/elections/206 [Budge et al. (2001), Klingemann et al. (2006) y Volkens et al. (2012)].

\subsection{Comparación con el énfasis y posición partidarios sobre la UE en Alemania, Francia, Grecia, Italia, Portugal y el Reino Unido}

Antes de observar la posición de los partidos españoles individualmente, nos preguntamos si los cambios tanto en la importancia como en la posición de los partidos españoles sobre la UE son semejantes a los acontecidos en otros Estados miembros de nuestro entorno.

En los gráficos 4 y 5 se representan la evolución de la importancia de la UE (indicador 1) y la posición sobre la Unión (indicador 2) de los partidos con representación parlamentaria en cada una de las elecciones generales celebradas desde 1986 en Alemania, Francia, España, Grecia, Italia, Portugal y el Reino Unido.

Vemos cómo la agenda política europea parece tener un impacto desigual en la importancia de la Unión como tena en la competición partidaria a nivel estatal. En España, Portugal y Grecia, los partidos dedican más atención a la CE/UE durante los primeros años de integración europea, en los dos primeros casos, o desde la creación de la Unión en Maastricht, en el tercero. Luego, la importancia de la UE cae, incluso en momentos de gran relevancia política europea, como durante las deliberaciones públicas de la Convención europea que gestó el fallido Tratado por el que se establece una Constitución para Europa (2002-2003), o, salvo en el caso de Grecia, con la 
integración monetaria, a finales de los años noventa y hasta la puesta en circulación de los billetes y monedas de euro en enero de 2002. Mientras, los partidos parlamentarios francesas o británico se interesan más por la UE durante estos grandes debates y avances del proceso de integración, o, en el caso de los franceses, alemanes, italianos y hasta portugueses, a raíz de la gestión europea de la crisis que se inicia en 2007.

Gráfico 4: Cambios en la importancia (indicador 1) y la posición (indicador 2) sobre la UE en Alemania, Francia, España, Grecia, Italia, Portugal y el Reino Unido (todos los partidos con representación parlamentaria)

Gráfico 5: Cambios en la importancia (indicador 1) y la posición (indicador 2) sobre la UE en Alemania, Francia, España, Grecia, Italia, Portugal y el Reino Unido (todos los partidos con representación parlamentaria)

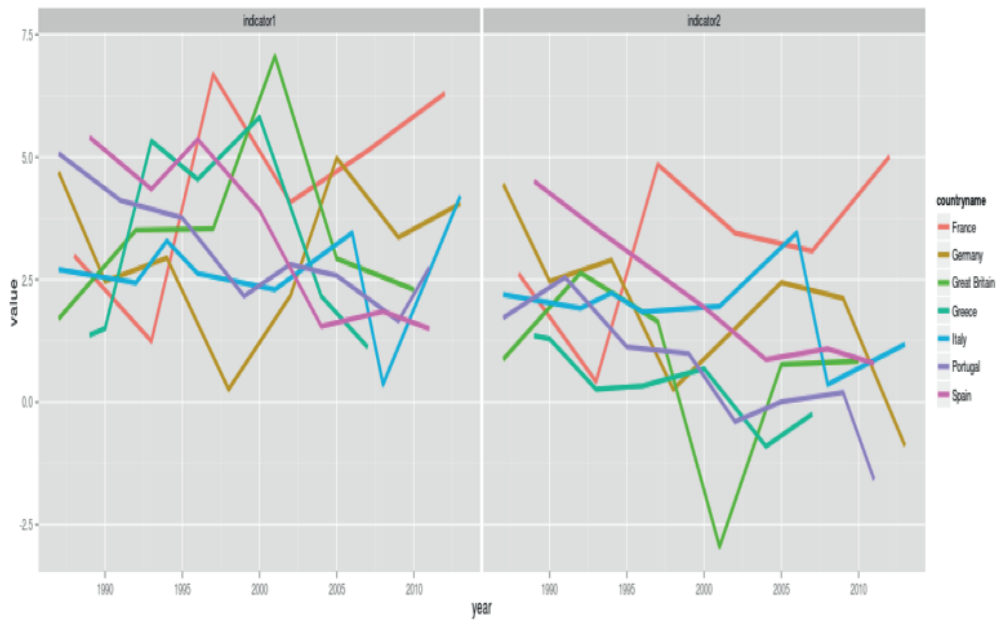

Fuente: Volkens, A. / Lehmann, Pola / Matthieß, Theres / Merz, Nicolas / Regel, Sven / Werner, Annika (2015): Manifesto Corpus. Versión: 2015a. Berlín: WZB.

En cuanto a la posición sobre la UE, mientras que en países como Francia o Italia esta variable va de la mano de la importancia de la Unión como tema, de forma que más atención coincide con más apoyo parlamentario, no ocurre lo mismo en otros países. Señaladamente, el pico de importancia de la Unión para las fuerzas políticas británicas, que se produce con la salida del euro y en pleno debate constitucional, concuerda con su posición más contraria a la UE de la serie. Centrándonos en los cambios durante la Gran Recensión, la importancia de la UE crece, como para los franceses y los italianos, para los partidos alemanes y portugueses; pero, en estos dos últimos casos, empeora su posición acerca de la Unión. 
En el siguiente apartado volveremos a centrarnos en las fuerzas políticas españolas, pero las examinaremos no ya de forma agregada como hasta ahora sino individualmente.

\subsection{Posición sobre la UE de los distintos partidos españoles}

Los gráficos 6 y 7 reflejan la evolución de la posición sobre la CE/UE de los distintos partidos españoles. En el gráfico 6, están representados PP, PSOE, CiU, PNV y CC. En el gráfico 7, figuran IU, ERC y BNG. Empleamos dos gráficos en lugar de uno para poder ofrecer una representación más clara de los cambios en esta variable.

Desde el año 1993, todos los partidos del gráfico 6 tienen una posición sobre la UE por encima o coincidente con la media, y los del gráfico 7 , por debajo de la media. Los partidos representados en el gráfico 7, ERC, IU y BNG mantuvieron una posición contraria al Tratado por el que se establece una Constitución para Europa, apoyado por las fuerzas del gráfico 6 , y por el $76,72 \%$ de los votantes, con una abstención del $57,67 \%$, en el referéndum consultivo celebrado el 20 de febrero de 2005.

Gráfico 6: Evolución de la posición sobre la UE de PP, PSOE, CiU, PNV y CC

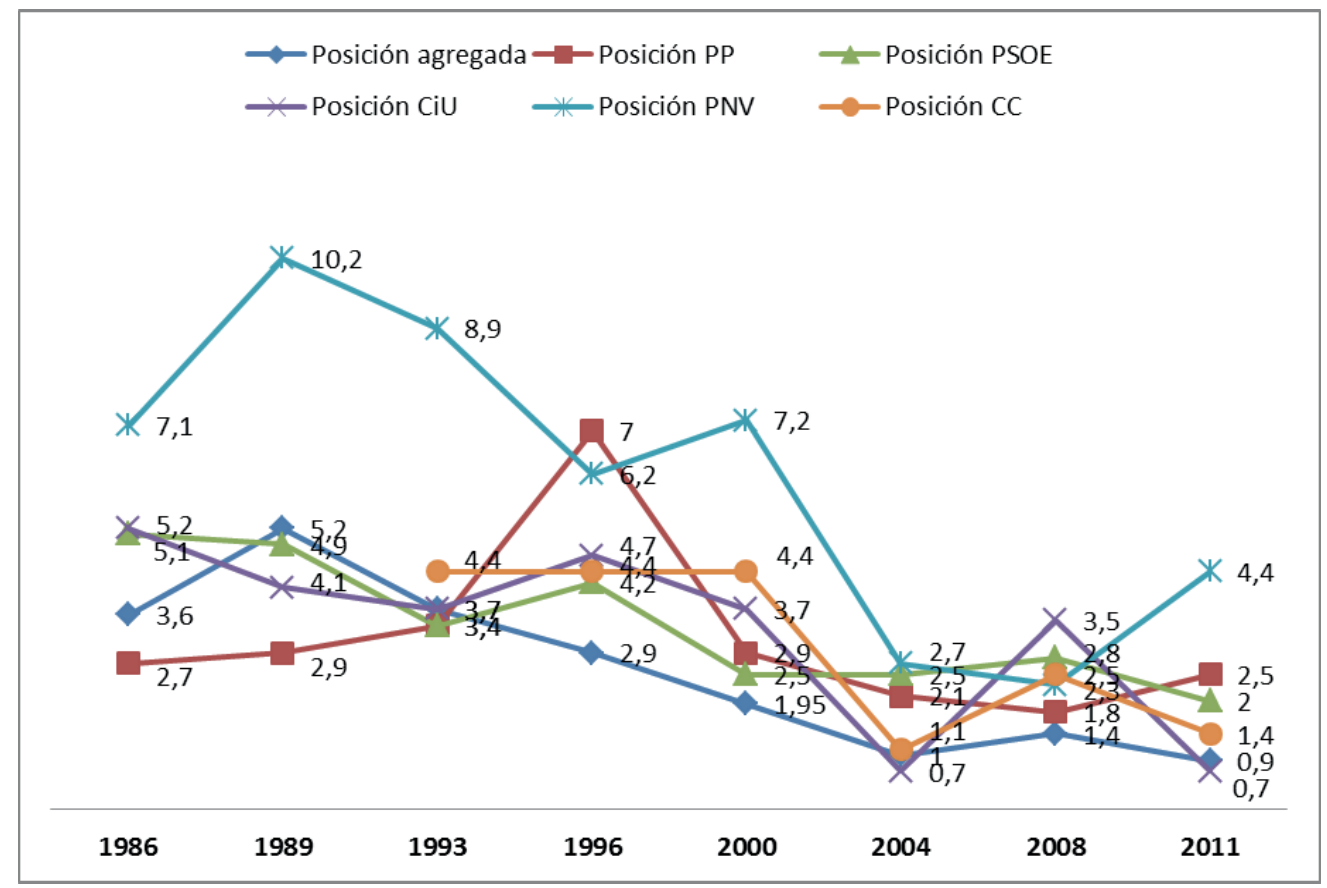

Fuente: Elaboración propia, empleando datos del Manifesto Project Accesibles en: https://manifestoproject.wzb.eu/elections/206 [Budge et al. (2001), Klingemann et al. (2006) y Volkens et al. (2012)] 
Gráfico 7: Evolución de la posición sobre la UE de IU, ERC y BNG

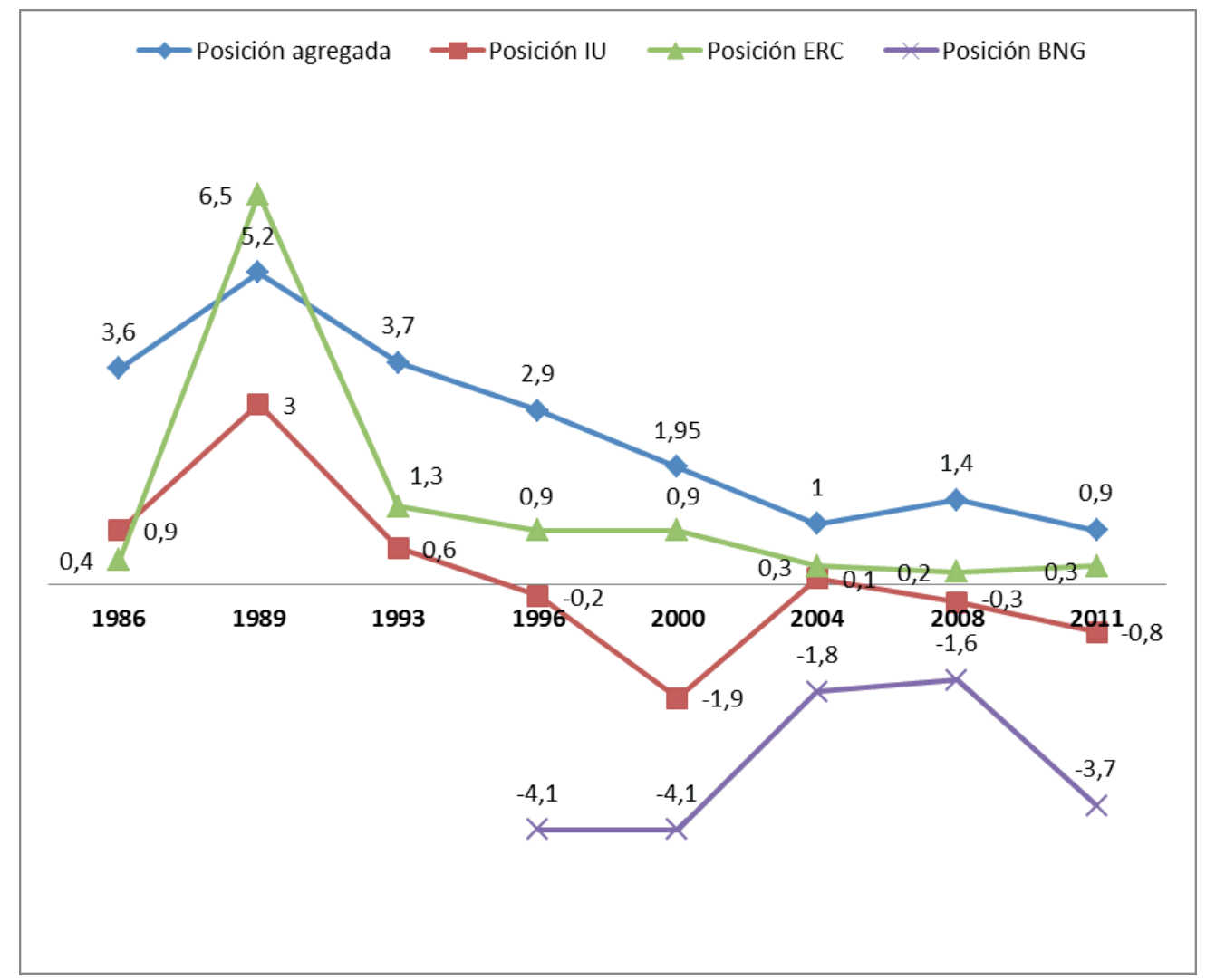

Fuente: Elaboración propia, empleando datos del Manifesto Project Accesibles en:

https://manifestoproject.wzb.eu/elections/206 [Budge et al. (2001), Klingemann et al. (2006) y

Volkens et al. (2012)]

La posición sobre la UE alcanza su máximo en las elecciones de 1989 para PSOE, IU, PNV y ERC. En las de 1996, para PP y CiU. Y, en las del año 2000, para CC. EL BNG es la única fuerza con un posicionamiento negativo en todas las elecciones. Mejora su posición en los comicios de 2004 y 2008; sin embargo, vuelve a empeorarla en los de 2011, en plena Gran Recensión.

En conjunto, el papel de la UE en la competición partidaria y el apoyo de los partidos españoles a la Unión es cada vez menor, en contraste con la continua profundización de la integración y el creciente número de decisiones públicas que se adoptan en el nivel supranacional, entre otros actores, por parte de los Primeros Ministros elegidos indirectamente en las elecciones generales y sus Ministros. Esta tendencia sorprende todavía más en la Europa de la Gran Recesión, y, como hemos visto, es contraria a la 
experimentada en países como Francia o Italia, donde crece la atención y el apoyo a la Unión de las fuerzas parlamentarias, desde 2002, en el primer caso y desde 2006 en el segundo. Incluso en Portugal, en los últimos años, crece la importancia de los temas de la UE; aunque, decrece el apoyo de los partidos a la Unión.

En el siguiente apartado dejamos de tratar a la UE como un único tema y observamos la oferta de los partidos españoles sobre los diferentes asuntos de la UE en la campaña de las elecciones generales de 2011. Aplicando la teoría de la importancia, no aguardamos competición directa sobre los temas de la Unión ni una oferta partidaria bien diferenciada. Iremos detallando cómo los datos corroboran estas expectativas, primero considerando los programas de todos los partidos, y después el debate televisado y las cuentas en twitter de los candidatos a la presidencia del gobierno del PP y el PSOE.

\section{Los asuntos de la UE en las elecciones generales de 2011}

\subsection{Propuestas sobre temas de la UE en los programas de 2011}

Los asuntos de la UE que reciben mayor atención en las elecciones generales de 2011 son, en primer lugar, los económicos y monetarios (45 propuestas programáticas). A continuación, Agricultura y desarrollo rural (23 medidas); Espacio de Libertad, Seguridad y Justicia (22); Política Exterior y Política de Vecindad (19); y Fiscalidad (18). Se puede consultar la tabla de frecuencias en el apéndice (tabla 9).

Aplicando las tres áreas de nuestro esquema, los partidos prestan más atención al área 3 Políticas Públicas, en la que se integran las cinco categorías anteriores. A pesar del debate sobre la necesidad de reformar las instituciones en la zona euro para facilitar la gestión de la crisis, y también del aumento del descontento ciudadano en España con el funcionamiento de la democracia a escala nacional y europea, los partidos españoles desenfatizan en 2011 los asuntos de la UE de las áreas 1 y 2, Proceso de Integración, e Instituciones y Actores.

No hay relación entre la distribución de competencias entre la UE y los Estados y el número de propuestas por tema. De hecho, en las cinco categorías que concentran más propuestas la extensión de la acción de la Unión es muy variable. Nos encontramos con las áreas de políticas con mayor presencia de elementos intergubernamentales, como interior y sobre todo Política Exterior, fiscalidad, que es un asunto a día de hoy de competencia estatal, y también con ámbitos en los que las instituciones supranacionales gozan de extensas atribuciones, como agricultura y moneda en un país miembro de la eurozona. Sin embargo, como podemos comprobar también en la tabla de frecuencias del apéndice (tabla 9), en materias en las que las instituciones de la UE tienen atribuidas extensas competencias, como comercio (y ante negociaciones comerciales de enorme transcendencia, como el acuerdo de libre comercio con Estados Unidos), mercado interior o medioambiente, apenas se hacen propuestas. Tampoco, por ejemplo, en las categorías agenda digital, energía o transportes, asuntos que ocupan un lugar central en la agenda política europea en este momento.

Centrándonos en los dos partidos con posibilidades de encabezar el Gobierno central en 2011, PP y PSOE, como refleja el gráfico 10, el primero enfatiza los Asuntos 
económicos y monetarios (11 propuestas programáticas), mientras que el segundo dedica casi tanta atención a éstos (7 medidas), como a los de la categoría Fiscalidad (6), que desenfatiza el PP. El PSOE presta atención además a las Políticas Exterior y de Vecindad (6 propuestas), así como a una categoría del área 2 Instituciones y órganos de la UE (2), que igualmente desenfatiza el PP.

Gráfico 8: Asuntos europeos prioritarios en las elecciones generales de 2011 (todos los partidos con representación parlamentaria)

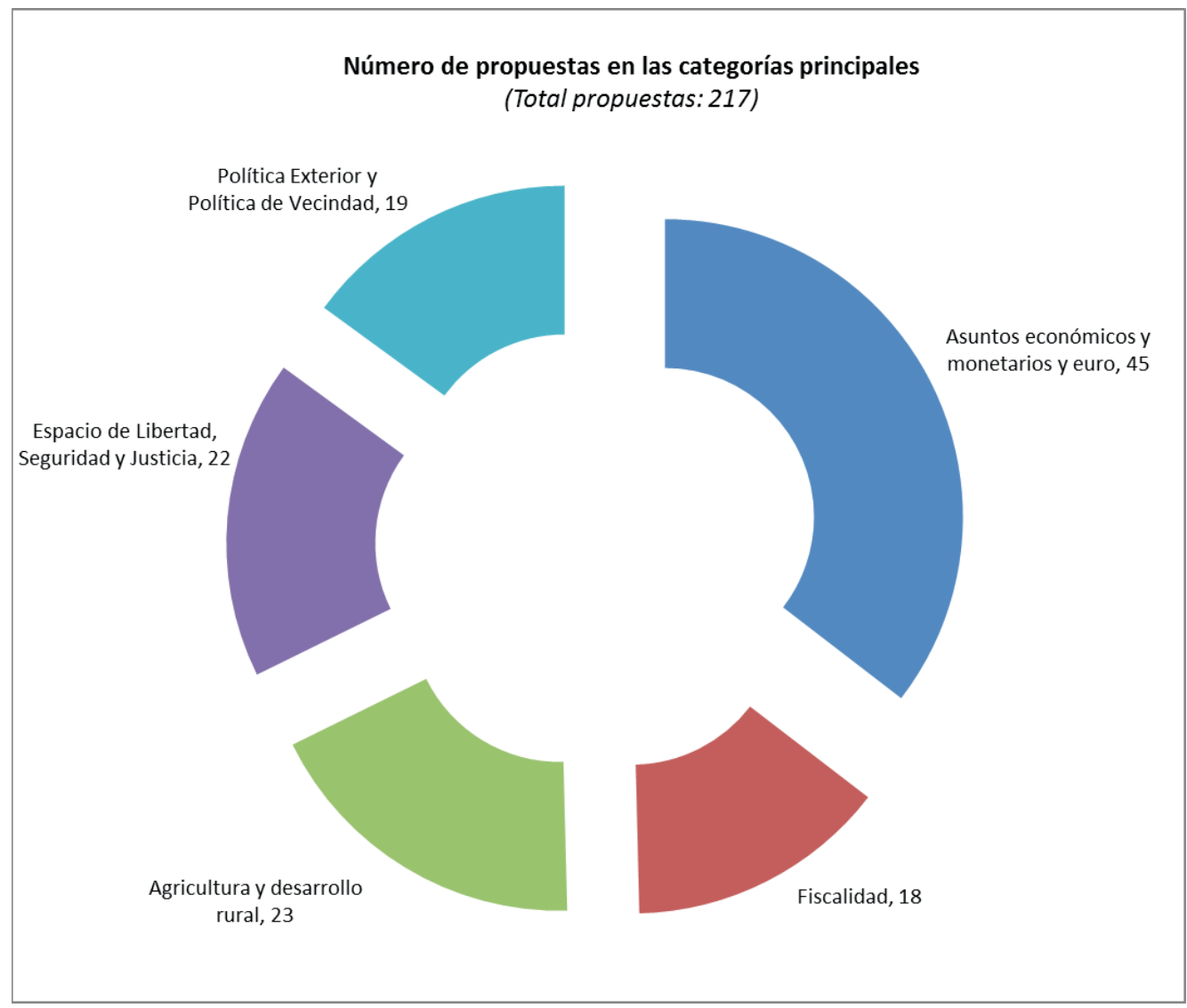

Fuente: Elaboración propia. 
Gráfico 9: Asuntos de la UE prioritarios para el PP y el PSOE en 2011

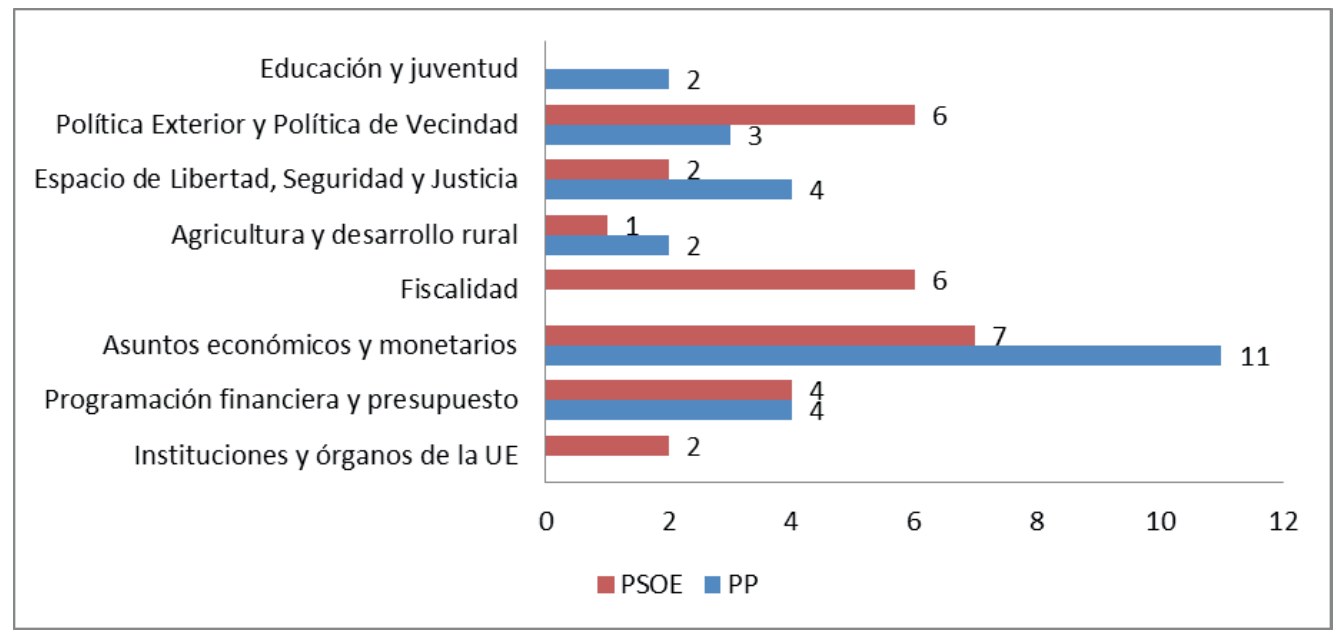

Fuente: Elaboración propia.

A continuación, para demostrar en qué medida en las elecciones generales de 2011 la competición partidaria se limita a la (des)enfatización de asuntos de la UE, ponemos el foco en las cinco categorías en las que los partidos presentan más propuestas sobre estos temas (gráfico 5 ). ${ }^{17}$

En primer lugar, la tabla 1 contiene las 45 medidas de la categoría de la UE con mayor presencia en esta campaña: Asuntos económicos y monetarios.

Llama la atención, por una parte, la coincidencia entre PP, PSOE, CiU, PNV y CC a la hora de incluir distintas propuestas, muchas de ellas formuladas de forma vaga, en la línea de profundizar la integración económica: mayor coordinación/integración económica, creación de una capacidad efectiva de supervisión y de garantía de depósito común, o avances hacia una supervisión integrada. Mientras, solo el PP propone la "estricta observancia del pacto de estabilidad y crecimiento", al tiempo que otros de los anteriores partidos enfatizan propuestas contrarias o alternativas. Así, el PSOE presenta medidas de estímulo, como que el Mecanismo Europeo de Estabilidad Financiera (MEDE) no solo asista a países con dificultades de financiación sino que también financie planes de inversión, o de fortalecimiento de las instituciones supranacionales como el Parlamento Europeo en materia económica. El PNV ofrece la creación de un Ministerio de Economía a nivel europeo, que gestione los recursos del Fondo Europeo de Estabilidad Financiera, y la creación de eurobonos. Por otro parte, partidos como el

${ }^{17}$ Los lectores interesados en conocer la oferta partidaria en las demás categorías de nuestro esquema pueden contactarnos por correo electrónico (cristina.ares@usc.es). 
BNG y sobre todo IU, Compromís-Q y Geroa Bai, prácticamente se limitan a enfatizar propuestas distantes de las de los partidos anteriores. Por ejemplo, IU solo presenta dos medidas claras: alargar hasta 2016 el plazo para reducir el déficit al 3\%, y un cambio completo del Pacto del euro. El BNG ofrece anular el Pacto de Estabilidad, o modificar el mandato del BCE estableciendo como objetivos prioritarios la estabilidad económica y la creación de empleo.

En segundo lugar, examinamos las 23 propuestas programáticas codificadas en la categoría Agricultura y desarrollo rural.

Es preciso subrayar cómo la oferta en esta categoría de los dos partidos con aspiraciones en 2011 a detentar la Presidencia del Gobierno se limita a manifestar su apoyo a una Política Agrícola Común (PAC) fuerte con una dotación financiera suficiente. La desenfatización de la PAC por parte de PP y PSOE choca con la importancia estratégica del sector en la economía española, con factores europeos como la importancia relativa de esta rúbrica en el presupuesto de la UE todavía en nuestros días, e incluso con el hecho de que durante la campaña de 2011 se estuviese negociando en Bruselas la última reforma de la PAC.

El partido español que pone más énfasis durante esta campaña en los temas agrarios es IU. Esta fuerza política destaca asimismo medidas más concretas como una nueva PAC para defender la agricultura familiar, poner coto al control de la cadena agroalimentaria por parte de las grandes empresas, o reorientar el modelo ganadero y que estas políticas se establezcan en el marco de la soberanía alimentaria; corrección del recorte de las ayudas directas del primer pilar de la PAC; o rechazo de los Acuerdos con Marruecos y Mercosur.

Finalmente, los partidos de ámbito no estatal, al igual que el PP y el PSOE, desenfatizan la Agricultura y el desarrollo rural a pesar de su importancia para la economía española y en la política europea. Al igual que IU, aportan propuestas mejor definidas, como la adaptación de la PAC a las características del medio rural de sus territorios respectivos (CiU, PNV, BNG, CC, Compromís-Q, Geroa Bai) y/o una mayor participación de las autoridades regionales en la elaboración de la PAC (CiU, ERC, Geroa Bai).

En tercer lugar, ponemos el foco en las 22 medidas de la categoría Espacio de Libertad, Seguridad y Justicia (ELSJ) (22). 
Tabla 1: Propuestas programáticas sobre asuntos económicos y monetarios y euro

\begin{tabular}{|c|c|}
\hline Agente & Propuesta \\
\hline PP & $\begin{array}{l}\text { Mayor coordinación económica (pág. 198) } \\
\text { Mejora de los criterios de gobernanza de la eurozona (pág. 198) } \\
\text { Mayor integración económica (pág. 198) } \\
\text { Aumentaremos el nivel general de transparencia (pág. 198) } \\
\text { Creación de una capacidad efectiva de supervisión y de garantía } \\
\text { de depósitos común (pág. 198)/Avances hacia una supervisión } \\
\text { auténticamente integrada (pág. 199) } \\
\text { Estricta observancia del pacto de estabilidad y crecimiento (pág. 199) } \\
\text { Saneamiento de los bancos europeos (pág. 199) } \\
\text { Regularemos los productos derivados y las ventas a corto (pág. 199) } \\
\text { Transparencia en las relaciones entre las entidades financieras y sus } \\
\text { clientes (pág. 199) } \\
\text { Establecimiento de fondos de garantía de depósitos a nivel europeo } \\
\text { (pág. 199) } \\
\text { Creación de un instrumento específico para financiar pymes en la UE } \\
\text { (pág. 199) }\end{array}$ \\
\hline PSOE & $\begin{array}{l}\text { Reforzar las instituciones de gobierno económico (pág. 133) } \\
\text { Mejor coordinación de las políticas económicas (pág. 133) } \\
\text { Construcción de una auténtica unión económica (pág. 133) } \\
\text { Flexibilización del Mecanismo Europeo de Estabilidad Financiera } \\
\text { (MEDE) para que, además de articular ayudas a países con } \\
\text { dificultades financieras, financie planes de inversión y estímulo, para } \\
\text { dar solución, no solo al problema del endeudamiento, sino también } \\
\text { a la falta de crecimiento económico necesario para la creación de } \\
\text { empleo (pág. 134) } \\
\text { Agencia Europea de Calificación de Riesgos, que evalúe de forma } \\
\text { independiente el estado real de las finanzas de los Estados miembros } \\
\text { (pág. 134) } \\
\text { Mejoras en la regulación de las agencias privadas de evaluación de } \\
\text { riesgos, para aumentar la competencia europea en este sector (pág. } \\
\text { 134) } \\
\text { Ampliación de las competencias del Parlamento Europeo en } \\
\text { el terreno económico y financiero, con lo que ganaríamos en } \\
\text { eficacia, rapidez y margen de maniobra, además de en legitimidad } \\
\text { democrática (pág. 134) }\end{array}$ \\
\hline
\end{tabular}




\begin{tabular}{|l|l|}
\hline Agente & Propuesta \\
\hline CiU & $\begin{array}{l}\text { Armonización económica para consolidar la Eurozona, eliminando } \\
\text { los desequilibrios que padece actualmente (pág. 19) } \\
\text { Puesta en marcha de los eurobonos, que, junto con la consolidación } \\
\text { fiscal, nos ayudarán a salir de la crisis (pág. 19) } \\
\text { Compromiso con el euro y la estabilidad financiera de la Unión } \\
\text { Monetaria (pág. 19) } \\
\text { Celeridad para cubrir las lagunas de reglamentación y supervisión de } \\
\text { los mercados financieros (pág. 19) }\end{array}$ \\
\hline IU & $\begin{array}{l}\text { Cambio completo del Pacto del Euro (pág. 17) } \\
\text { De modo transitorio, apoyaremos las propuestas de aumentar el plazo } \\
\text { para reducir el déficit al 3\% al 2016 (pág. 17) }\end{array}$ \\
\hline ERC & $\begin{array}{l}\text { Mayor supervisión de las entidades financieras desde el Banco } \\
\text { Central Europeo y la Comisión (pág. 23) } \\
\text { Creación de un Ministerio de Economía a nivel europeo, que cuente } \\
\text { con los recursos e instrumentos adecuados de política económica, } \\
\text { que gestione los recursos del Fondo Europeo para la Estabilidad } \\
\text { Financiera (pág. 30) } \\
\text { Los recursos para garantizar los pagos de la deuda de los países que } \\
\text { necesiten ayuda han de ser suficientes (pág. 30) } \\
\text { Creación de eurobonos que con un rating de deuda europea } \\
\text { financien el déficit de los diferentes páses, reduciendo el coste del } \\
\text { endeudamiento de los países que pagan enormes diferenciales en } \\
\text { relación a la deuda alemana (pág. 30) } \\
\text { El Banco Central Europeo debe facilitar a las entidades financieras la } \\
\text { liquidez que precisan para que puedan otorgar préstamos a familias y } \\
\text { a empresas (pág. 30) }\end{array}$ \\
\hline PNV & $\begin{array}{l}\text { Promover la mejora del marco de regulación y supervisión del } \\
\text { sistema financiero europeo (pág. 12) }\end{array}$ \\
\hline $\begin{array}{l}\text { Incidir en la política monetaria aplicada por el Banco Central } \\
\text { Europeo (pág. 17) }\end{array}$ \\
\hline
\end{tabular}




\begin{tabular}{|c|c|}
\hline Agente & Propuesta \\
\hline $\mathrm{BNG}$ & $\begin{array}{l}\text { Vinculación de la política monetaria a instituciones democráticas, } \\
\text { acometiendo la conversión del actual estatus de independencia del } \\
\text { BCE (pág. 8) } \\
\text { El objetivo prioritario de la política monetaria será la estabilidad } \\
\text { económica y la creación de empleo (pág. 8) } \\
\text { Anulación del Pacto de Estabilidad, dando paso a la aplicación de } \\
\text { otros criterios rectores de la política económica basados en el apoyo } \\
\text { a la inversión productiva a través del fomento económico de los } \\
\text { sectores estratégicos, el derecho a producir de los pueblos, la garantía } \\
\text { de las políticas sociales, así como la promoción de la redistribución } \\
\text { económica, social y territorial (pág. 8) } \\
\text { Estricta supervisión de las entidades y agencias del sector financiero } \\
\text { (pág. 8) } \\
\text { Emisión de eurobonos, dando soporte directo desde el BCE a } \\
\text { las necesidades de financiación de los Estados, sin que implique } \\
\text { cesiones adicionales de soberanía o competencias a instituciones } \\
\text { comunitarias (pág. 8) }\end{array}$ \\
\hline $\mathrm{CC}$ & $\begin{array}{l}\text { Aumentar la capacidad financiera y la flexibilidad del uso del Fondo } \\
\text { Europeo de recuperación (pág. } 88 \text { ) } \\
\text { Incluir entre los objetivos del BCE el desarrollo económico } \\
\text { sostenible (pág. 88) } \\
\text { Agencia de calificación europea (pág. 88) } \\
\text { Coyunturalmente debe crearse un mercado de eurobonos (pág. 88) }\end{array}$ \\
\hline Compromís-Q & $\begin{array}{l}\text { Agencia de calificación económica de ámbito europeo (pág. 68) } \\
\text { Obligación a los miembros de la UE receptores de ayudas } \\
\text { económicas de, además de practicar la disciplina fiscal, adoptar } \\
\text { medidas de crecimiento estructural a medio y largo plazo (pág. 68) }\end{array}$ \\
\hline Geroa Bai & $\begin{array}{l}\text { Agencia de rating europea que se mueva por el interés público (pág. } \\
\text { 17) } \\
\text { Reforma del BCE para que pueda prestar dinero directamente a los } \\
\text { Estados para financiar su deuda (pág. 17) } \\
\text { Cambiar el tipo de interés que el BCE cobra a los bancos, de manera } \\
\text { que siga siendo el } 1 \% \text { solo para los fondos destinados a incrementar } \\
\text { el crédito a empresas, incluyendo pymes y autónomos, y aumentando } \\
\text { el tipo significativamente para los fondos que los bancos destinen a } \\
\text { la compra de deuda pública (pág. 17) }\end{array}$ \\
\hline
\end{tabular}

Fuente: Elaboración propia. 
Tabla 2: Propuestas programáticas sobre agricultura y desarrollo rural

\begin{tabular}{|c|c|}
\hline Agente & Propuesta \\
\hline PP & $\begin{array}{l}\text { Defenderemos una Política Agrícola Común (PAC) fuerte, dotada de } \\
\text { medios suficientes para nuestro sector agrícola y ganadero (pág. 199) } \\
\text { Afianzar la seguridad alimentaria de Europa (pág. 199) }\end{array}$ \\
\hline PSOE & $\begin{array}{l}\text { Defenderemos una PAC fuerte, más simple, con una dotación } \\
\text { financiera suficiente y asentada en sus tres instrumentos básicos: } \\
\text { apoyo a las rentas, gestión de mercados y desarrollo rural (pág. 32) }\end{array}$ \\
\hline $\mathrm{CiU}$ & $\begin{array}{l}\text { La PAC 2014-2020 será lo más adecuada posible a las características } \\
\text { productivas del medio agrario y rural catalán dando cabida en el } \\
\text { marco regulador a las singularidades de la realidad mediterránea } \\
\text { (pág. 29) } \\
\text { Regionalizar la PAC, de forma que las regiones tengan capacidad } \\
\text { de decisión en algunos aspectos y se incremente la autonomía de } \\
\text { gestión para poder adaptar determinadas decisiones a los sistemas } \\
\text { productivos regionales y ser más ágiles en la gestión (pág. 30) } \\
\text { Territorializar las ayudas europeas, transfiriendo las dotaciones } \\
\text { finalistas inmediatamente a las Comunidades Autónomas (pág. 30) }\end{array}$ \\
\hline IU & $\begin{array}{l}\text { Nueva PAC capaz de defender la agricultura familiar, proteger al } \\
\text { medio ambiente y poner coto al control de la cadena agroalimentaria } \\
\text { por parte de las grandes empresas (págs. } 31 \text { y 68) } \\
\text { Aprovechar la reforma de la PAC para reorientar el modelo } \\
\text { agroganadero y que las políticas agrarias y alimentarias se } \\
\text { establezcan en el marco de la soberanía alimentaria (pág. } 31 \text { ) } \\
\text { La PAC debe incluir instrumentos de regulación de mercado que } \\
\text { pongan fin a la especulación alimentaria y a la volatilidad de los } \\
\text { precios, y el abuso de poder de la agroindustria y la gran distribución } \\
\text { (pág. 68) } \\
\text { Rechazo de los Acuerdos con Marruecos y Mercosur (pág. 69) } \\
\text { Rechazo del recorte del } 15 \% \text { en la PAC para 2014-2020 (pág. 69) } \\
\text { Corrección del recorte de las ayudas directas del primer pilar (pág. } \\
\text { 69) }\end{array}$ \\
\hline PNV & $\begin{array}{l}\text { La reforma de la PAC es una amenaza para nuestros productores. } \\
\text { Seguiremos trabajando para conseguir las mejores condiciones para } \\
\text { los sectores agrícola, ganadero y de transformación vinculados (pág. } \\
\text { 15) }\end{array}$ \\
\hline
\end{tabular}




\begin{tabular}{|c|c|}
\hline Agente & Propuesta \\
\hline UPyD & $\begin{array}{l}\text { Reforma de la PAC que defienda una agricultura acorde con una serie } \\
\text { de criterios en relación a los pagos directos, como: la posibilidad de } \\
\text { vincularlos al núm. de trabajadores por explotación y no por hectárea } \\
\text { (redefiniendo el concepto de "agricultor activo"), un componente } \\
\text { ecológico obligatorio, un mínimo para los pequeños agricultores, etc. } \\
\text { (pág. 20) } \\
\text { Las medidas de mercado de la PAC reforzarán la posición } \\
\text { del agricultor en la cadena alimentaria, mediante una serie de } \\
\text { disposiciones como: una norma europea que controle el poder de } \\
\text { las grandes distribuidoras, la promoción de las organizaciones de } \\
\text { autogestión en pequeñas y medianas explotaciones, la concreción } \\
\text { de la noción de "stock de alimentos" con el fin de garantizar la } \\
\text { seguridad alimentaria, precio de activación más relacionado con los } \\
\text { mercados reales, etc. (pág. 20) } \\
\text { Apoyo y reforzamiento de las zonas rurales a través de: medidas de } \\
\text { ayuda a los jóvenes agricultores, facilidades para los intercambios } \\
\text { de buenas prácticas, el desarrollo de un sector agrícola eficiente, } \\
\text { competitivo y que contribuya al desarrollo sostenible (págs. } 20 \text { y 21) }\end{array}$ \\
\hline ERC & $\begin{array}{l}\text { Cataluña estará representada en la UE con voz y voto en materia de } \\
\text { Agricultura (pág. 177) }\end{array}$ \\
\hline $\mathrm{BNG}$ & $\begin{array}{l}\text { Mantenimiento de los mecanismos de intervención pública en } \\
\text { los mercados agrarios que resulten eficaces para suavizar las } \\
\text { oscilaciones de precios (pág. 22) } \\
\text { Normativas que mejoren la regulación del precio de referencia de } \\
\text { la leche, y, con carácter extensivo, de otros productos alimentarios, } \\
\text { de manera que se tengan en cuenta los costes de producción y } \\
\text { se garantice la transparencia en la formación de los precios que } \\
\text { erradique las ganancias especulativas (pág. 22) }\end{array}$ \\
\hline $\mathrm{CC}$ & $\begin{array}{l}\text { Tratamiento diferenciado para las regiones ultraperiféricas (RUPs) } \\
\text { ante futuras reformas de la PAC. Por ejemplo, diseño de políticas } \\
\text { específicas de desarrollo rural para las RUPs o flexibilización de la } \\
\text { aplicación de las directrices europeas sobre ayudas estatales al sector } \\
\text { agrario y forestal (pág. 38) }\end{array}$ \\
\hline Compromís-Q & $\begin{array}{l}\text { Defensa prioritaria de los intereses del sector agrario valenciano en la } \\
\text { negociación y aplicación de la nueva PAC, prevista para el horizonte } \\
2014-2020 \text { en la firma de acuerdos con terceros países y en los } \\
\text { ámbitos de la OMC (pág. 20) }\end{array}$ \\
\hline
\end{tabular}




\begin{tabular}{|l|l|}
\hline Agente & Propuesta \\
\hline Foro Asturias & $\begin{array}{l}\text { Reforma de la PAC que reconozca las singularidades de la actividad } \\
\text { agraria en España (pág. 30) }\end{array}$ \\
\hline Geroa Bai & $\begin{array}{l}\text { Participación activa de Navarra en los foros europeos en los que se } \\
\text { fijen las principales líneas de las política agrícola (pág. 38) }\end{array}$ \\
\hline
\end{tabular}

Fuente: Elaboración propia.

Tabla 3: Propuestas programáticas sobre el Espacio Europeo de Libertad, Seguridad y Justicia

\begin{tabular}{|l|l|}
\hline Agente & Propuesta \\
\hline PP & $\begin{array}{l}\text { Potenciación del espacio de seguridad (pág. 182) } \\
\text { Fortalecimiento de los instrumentos europeos de cooperación policial } \\
\text { y judicial (pág. 187) } \\
\text { Construcción de una política común de inmigración y firma de } \\
\text { acuerdos con países terceros (pág. 198) } \\
\text { Consolidación del Espacio de Libertad, Seguridad y Justicia, } \\
\text { con atención especial a la lucha contra el terrorismo y el crimen } \\
\text { organizado (pág. 198) }\end{array}$ \\
\hline PSOE & $\begin{array}{l}\text { Garantizar la libre circulación dentro del espacio europeo (pág. 109) } \\
\text { Potenciaremos los compromisos de Schengen en materia de control } \\
\text { fronterizo común externo (pág. 109) }\end{array}$ \\
\hline $\begin{array}{l}\text { IU } \\
\text { Abordar la inmigración como un hecho estructural que transforma } \\
\text { y enriquece a la sociedad receptora, lo que implica el necesario } \\
\text { desarrollo de un conjunto de políticas que se orienten de una } \\
\text { forma activa hacia una ciudadanía basada en los principios de la } \\
\text { universalidad de los derechos humanos y la interculturalidad (pág. } \\
\text { 63) }\end{array}$ \\
\hline
\end{tabular}




\begin{tabular}{|c|c|}
\hline Agente & Propuesta \\
\hline UPyD & $\begin{array}{l}\text { Instaurar un sistema legislativo europeo unificado en materia de } \\
\text { inmigración. Entretanto, sincronizar las diferentes legislaciones } \\
\text { nacionales, asegurando la cooperación entre Estados miembros (pág. } \\
\text { 29) } \\
\text { Transferir a la UE la gestión de las políticas de ciudadanía e } \\
\text { inmigración mediante un Servicio Europeo de Inmigración que } \\
\text { implemente las políticas de integración y visados comunes (pág. 29) } \\
\text { Para mejorar la lucha contra las mafias de la inmigración ilegal, } \\
\text { refuerzo de la cooperación entre las instituciones europeas dedicadas } \\
\text { a combatir el crimen organizado, como EUROPOL o INTERPOL, } \\
\text { reduciendo la descoordinación entre los Estados miembros (pág. 29) } \\
\text { Política migratoria común, con el restablecimiento de la normativa } \\
\text { del espacio de Schengen, cancelando las excepciones de algunos } \\
\text { Estados miembros, y con una Carta Europea de los derechos de los } \\
\text { inmigrantes comunitarios (pág. 45) } \\
\text { Reparto más equitativo entre los Estados miembros de los costes de } \\
\text { control de inmigración en las puertas de entrada a la UE (pág. 45) } \\
\text { Red de centros de acogida de inmigrantes irregulares en todas las } \\
\text { regiones europeas (pág. 45) } \\
\text { Incremento de los tratados de la UE con terceros países en materia } \\
\text { de inmigración, contemplando aspectos como la regulación de flujos } \\
\text { migratorios, entre otros (pág. 45) } \\
\text { Un sistema de "Green Card" que permite a los ciudadanos de } \\
\text { terceros países disponer de un permiso conjunto de residencia y } \\
\text { trabajo en la UE (pág. 46). }\end{array}$ \\
\hline $\mathrm{CC}$ & $\begin{array}{l}\text { Una estrategia integral para abordar el fenómeno migratorio, basada } \\
\text { en la solidaridad entre los Estados, y en la corresponsabilidad de los } \\
\text { distintos niveles, regional, estatal y europeo, que incluya el refuerzo } \\
\text { de la cooperación con los países de origen (pág. 74) } \\
\text { Medidas para ordenar los flujos migratorios y favorecer la } \\
\text { integración de los inmigrantes legales (pág. 74) } \\
\text { Medidas eficaces de lucha contra la inmigración irregular (pág. 74) }\end{array}$ \\
\hline Compromís-Q & $\begin{array}{l}\text { Política migratoria común, y criterios comunes para el control } \\
\text { de fronteras, la lucha contra las redes mafiosas que trafican con } \\
\text { personas, etc. (pág. 55) } \\
\text { Contribución a la resolución del problema de las pateras, mediante } \\
\text { convenios sobre flujos de entrada con los países africanos (pág. 55) } \\
\text { Contundencia en la exigencia a los países africanos del } \\
\text { reconocimiento y la repatriación de las personas llegadas de manera } \\
\text { irregular (pág. 55) }\end{array}$ \\
\hline
\end{tabular}

Fuente: Elaboración propia. 
PP y PSOE persisten en su estrategia de desenfatizar temas de la Unión, a pesar de la relevancia del tema para España y la UE en su conjunto. Ambos partidos se limitan a manifestar vagamente su conformidad con la consolidación o el fortalecimiento del ELSJ en su actual diseño.

El partido español que más énfasis pone en este asunto en 2011 es UPyD. Lo hace además para apoyar con claridad una mayor integración europea en esta materia y apuntar medidas concretas como la creación de un Servicio Europeo de Inmigración, una red de centros de acogida de inmigrantes irregulares en todas las regiones europeas, o un sistema de "tarjeta verde" que permita a los ciudadanos de terceros Estados disponer de un permiso conjunto de residencia y trabajo en la UE.

En cuarto lugar, analizamos las 19 propuestas acerca de las Políticas Exterior y de Vecindad (19).

Tabla 4: Propuestas programáticas sobre Política Exterior y Política de Vecindad

\begin{tabular}{|c|c|}
\hline Agente & Propuesta \\
\hline $\mathrm{PP}$ & $\begin{array}{l}\text { Impulso a la Política Exterior (pág. 198-9) y al Servicio Europeo de } \\
\text { Acción Exterior (pág. 198) } \\
\text { Atención a los ámbitos mediterráneo e iberoamericano (pág. 199) }\end{array}$ \\
\hline PSOE & $\begin{array}{l}\text { Fomentar las Políticas de Vecindad y Gran Vecindad en el marco de } \\
\text { una acción concertada en África entre los Gobiernos de España y } \\
\text { Canarias, fomentando planes de cooperación (pág. 48) } \\
\text { Presencia unitaria de la UE en las organizaciones internacionales } \\
\text { más relevantes (pág. 134) } \\
\text { Mayor responsabilidad, visibilidad y dimensión política del } \\
\text { Presidente del Consejo de la Unión y la Alta Representante de la UE } \\
\text { para Asuntos Exteriores y Política de Seguridad (pág. 134) } \\
\text { Avances en el despliegue y capacitación del Servicio Europeo de } \\
\text { Acción Exterior (SEAE) (pág. 135) } \\
\text { Aplicación rigurosa de las Directrices de Derechos Humanos de la } \\
\text { UE por parte del SEAE (pág. 141) } \\
\text { Defenderemos un cambio profundo en la Política de Vecindad para } \\
\text { el Mediterráneo, a fin de que pase de primar la seguridad a primar la } \\
\text { democracia y los derechos humanos de forma efectiva (pág. 141) }\end{array}$ \\
\hline $\mathrm{CiU}$ & $\begin{array}{l}\text { El Mediterráneo ha de seguir siendo uno de sus ejes fundamentales } \\
\text { (pág. 119) } \\
\text { Lucharemos para crear una política exterior común (pág. 119) } \\
\text { La UE hablará con una sola voz en Naciones Unidas (pág. 120) }\end{array}$ \\
\hline
\end{tabular}




\begin{tabular}{|l|l|}
\hline Agente & Propuesta \\
\hline IU & $\begin{array}{l}\text { Cambiar sustancialmente la actual Política Exterior y de Vecindad de } \\
\text { la UE, que deben basarse en la paz, el desarme, la cooperación y las } \\
\text { relaciones internacionales democráticas (pág. 82) }\end{array}$ \\
\hline PNV & $\begin{array}{l}\text { Fortalecer la política exterior y el servicio diplomático europeo (pág. } \\
\text { 31) }\end{array}$ \\
\hline UPyD & $\begin{array}{l}\text { Política Exterior común, unificando la representación de los países } \\
\text { de la UE en los organismos internacionales; una única interlocución } \\
\text { internacional (pág. 45) }\end{array}$ \\
\hline Foro Asturias & $\begin{array}{l}\text { Fortalecimiento (pág. 87) } \\
\text { iberoamericanos (pág. 88) }\end{array}$ \\
\hline $\begin{array}{l}\text { Barcelona, capital de la política euromediterránea (pág. 169) } \\
\text { Contribuiremos a hacer avanzar la Política de Vecindad en la cuenca } \\
\text { mediterránea (pág. 169) }\end{array}$ \\
\hline
\end{tabular}

Fuente: Elaboración propia.

Salta a la vista cómo una vez más la estrategia de todas las fuerzas políticas se corresponde con las previsiones derivadas de la teoría de la importancia. En este tema, no obstante, PP y PSOE, sí se distancian. El primero lo desenfatiza, limitándose a incluir en su programa dos propuestas poco nítidas. Sin embargo, el PSOE le presta más atención. Manifiesta su preferencia por una mayor autonomía de las instituciones supranacionales en la acción exterior de la UE, y un cambio profundo en la Política de Vecindad para el Mediterráneo, a fin de que deje de centrarse en la seguridad para primar la democracia y los derechos humanos de forma efectiva. Sin poner énfasis en esta categoría, CiU y UPyD se posicionan también a favor de profundizar la integración en este ámbito. IU ofrece reformar ambas políticas en el mismo sentido que el PSOE. ERC plantea convertir a la ciudad de Barcelona en la capital de la política euromediterránea, y contribuir a impulsar la Política de Vecindad para el Mediterráneo.

En quinto lugar, estudiamos las 18 medidas sobre Fiscalidad. 
Tabla 5: Propuestas programáticas sobre fiscalidad

\begin{tabular}{|c|c|}
\hline Agente & Propuesta \\
\hline PP & No formula propuestas \\
\hline PSOE & $\begin{array}{l}\text { Mayor integración fiscal (pág. 133) } \\
\text { Fiscalidad europea propia, elaborada con criterios progresistas (pág. } \\
\text { 133) } \\
\text { Tasa sobre las transacciones financieras, orientada a reducir la } \\
\text { especulación (pág. 133) } \\
\text { Una imposición armonizada sobre las emisiones de CO2, facilitando } \\
\text { la transición a una Europa libre de CO2 (pág. 133) } \\
\text { Establecimiento de un Tesoro Europeo, un Ministerio de Hacienda } \\
\text { que, entre otras funciones, se ocupará de administrar los fondos } \\
\text { obtenidos a través de los impuestos europeos y de emitir deuda } \\
\text { pública europea (pág. 133) } \\
\text { Emisión de Eurobonos. Con ello, la UE conseguiría al menos tres } \\
\text { objetivos: reducir la especulación en los mercados financieros, } \\
\text { obtener más financiación y rebajar los precios a los que la UE se } \\
\text { financia (pág. 133) } \\
\text { Armonización fiscal. La UE necesita más capacidad para evitar la } \\
\text { competencia en materia fiscal (pág. 134) }\end{array}$ \\
\hline $\mathrm{CiU}$ & Armonización fiscal europea para consolidar la Eurozona (pág. 19) \\
\hline IU & $\begin{array}{l}\text { Intervenir en el proceso de tramitación de la futura Directiva sobre } \\
\text { el Impuesto de Transacciones Financieras (ITF) para anticipar su } \\
\text { entrada en vigor al } 1 \text { de enero de } 2013 \text { y para que el tipo mínimo } \\
\text { del impuesto sea del } 0,1 \% \text { en la compraventa de obligaciones y } \\
\text { acciones y del } 0,05 \% \text { en el caso de derivados, e incluir en el ITF las } \\
\text { operaciones con divisas (pág. 10) } \\
\text { Plantear ante las instituciones europeas la modificación del artículo } \\
56 \text { del Tratado de Funcionamiento para establecer como excepción } \\
\text { al principio de libertad de los movimientos de capitales, los } \\
\text { movimientos efectuados entre los Estados miembros y los territorios } \\
\text { calificados como paraísos fiscales (pág. 12) } \\
\text { Proponer que las instituciones europeas lideren las negociaciones } \\
\text { con las distintas Organizaciones internacionales de carácter político } \\
\text { o financiero para controlar e identificar a los verdaderos titulares de } \\
\text { esos movimientos de capitales (pág. 12) } \\
\text { Eliminación del billete de } 500 \text { euros (pág. 13) } \\
\text { Las facturas que sean pagadas en todo o en parte en metálico o } \\
\text { documentos al portador por importe superior a } 1.000 \text { euros no podrán } \\
\text { ser utilizadas como gastos deducibles (pág. 13) }\end{array}$ \\
\hline
\end{tabular}




\begin{tabular}{|l|l|}
\hline Agente & Propuesta \\
\hline PNV & $\begin{array}{l}\text { Tasa europea sobre las transacciones financieras, siempre y cuando } \\
\text { afecte prioritariamente a los movimientos de capitales de carácter } \\
\text { especulativo y su coste no se traslade a las operaciones básicas } \\
\text { cotidianas de ciudadanía y pequeñas empresas (pág. 25) }\end{array}$ \\
\hline UPyD & $\begin{array}{l}\text { Política fiscal común europea que complemente la moneda única } \\
\text { (págs. 14 y 45) } \\
\text { Creación de un Tesoro de la UE capaz de intervenir eficazmente en la } \\
\text { política monetaria y las crisis de financiación (pág. 45) }\end{array}$ \\
\hline Foro Asturias & $\begin{array}{l}\text { Armonización de determinados aspectos de la regulación del } \\
\text { impuesto sobre sociedades (pág. 47) } \\
\text { Lucha contra la existencia de paraísos fiscales en territorio europeo } \\
\text { (pág. 47) } \\
\text { Diseño y puesta en marcha de una clara política fiscal (pág. 87) }\end{array}$ \\
\hline
\end{tabular}

Fuente: Elaboración propia.

En esta materia, también conforme a nuestras previsiones, las estrategias de PP y PSOE vuelven a distanciarse. El primero desenfatiza la fiscalidad hasta el punto de no incluir ni una sola propuesta sobre este asunto. El segundo, por el contrario, al igual que IU, la enfatiza y presenta aportaciones concretas. Merece la pena destacar cómo el PSOE propone medidas sobre fiscalidad relativas tanto al proceso de integración (fiscalidad europea propia, deuda pública europea), como a las instituciones (establecimiento de un Ministerio de Hacienda Europeo), y al diseño de la política fiscal (progresista, tasa sobre las transacciones financieras).

IU asimismo enfatiza su apoyo al impuesto de transacciones financieras, proponiendo incluso anticipar su entrada en vigor, y a la progresividad fiscal; y llama la atención especialmente, sobre las medidas de lucha contra el fraude y los paraísos fiscales: modificación del artículo 56 del Tratado de Funcionamiento para excluir a los territorios calificados como paraísos fiscales del ámbito de aplicación de la libertad de movimiento de capitales, liderazgo por parte de las instituciones europeas en las negociaciones internacionales para controlar estos movimientos, o eliminar los billetes de 500 euros.

PNV y UPyD no enfatizan los asuntos fiscales; pero, se posicionan a favor, el primero, de la tasa europea sobre las transacciones financieras siempre que solo afecte a los movimientos de capitales de carácter especulativo, $\mathrm{y}$, el segundo, de la profundización de la integración fiscal con la creación de un Tesoro de la UE. 


\subsection{Propuestas sobre asuntos de la UE en el cara a cara Rajoy-Rubalcaba y en sus cuentas en la red social twitter}

Para finalizar este apartado, examinamos las propuestas comunicadas a través de dos canales alternativos al programa electoral: el debate televisado y las cuentas en la red social twitter de los candidatos con opciones de encabezar el Gobierno de España en 2011, Mariano Rajoy (PP) y Alfredo P. Rubalcaba (PSOE). Recordamos que en este artículo prestamos más atención al PP y al PSOE que a las demás fuerzas políticas únicamente porque el Presidente y los Ministros españoles son actores relevantes en la toma de decisiones en Bruselas, como miembros del Consejo Europeo y del Consejo de la Unión. El Parlamento nacional juega también un papel a escala europea; pero, secundario. ${ }^{18}$

Comenzamos con el único debate televisado, celebrado el 7 de noviembre. ${ }^{19}$ Conforme a nuestras expectativas derivadas de la teoría de la importancia, los candidatos del PP y del PSOE desenfatizan los asuntos de la UE. El candidato del PP no introduce ni una sola propuesta sobre estos temas. El candidato del PSOE enfatiza tres medidas de la categoría Asuntos económicos y monetarios, contenidas en la tabla 6. No se produce confrontación directa alguna de medidas sobre la Unión.

Tabla 6: Propuestas sobre la UE en el cara a cara Rajoy-Rubalcaba

\begin{tabular}{|l|l|l|}
\hline Agente & Categoría & Propuesta(s) \\
\hline Rajoy & Ninguna & No formula propuestas \\
\hline Rubalcaba & $\begin{array}{l}\text { Asuntos económicos } \\
\text { y monetarios y euro }\end{array}$ & $\begin{array}{l}\text { - Retraso de dos años, hasta 2015, del ajuste del } \\
\text { déficit en España } \\
\text { - Bajada de tipos de interés por parte del Banco } \\
\text { - Con sus 70.000 millones de euros el Banco Europeo } \\
\text { de Inversiones tiene que hacer un gran plan de } \\
\text { inversiones, que sería como un Plan Marshall para } \\
\text { Europa al que puedan concurrir las pymes }\end{array}$ \\
\hline
\end{tabular}

Fuente: Elaboración propia.

${ }_{18}$ En cambio, sobre la importancia de los asuntos de la UE en el Parlamento alemán, y cómo especialmente los partidos que conforman la coalición de Gobierno los enfatizan, puede consultarse Rauh (2014).

${ }^{19}$ El cara a cara se estructuró en tres bloques: 1) economía y empleo (de 20 minutos para cada candidato); 2) política social (15 minutos cada uno); 3) calidad democrática, posición de España en el mundo y política en general (10 minutos cada uno), precedidos de una primera intervención de dos minutos por candidato, y concluidos con un cierre sin referencias al partido rival, de tres minutos cada uno. 
Continuamos con la cuentas en twitter de Mariano Rajoy y Alfredo P. Rubalcaba. ${ }^{20} \mathrm{Se}$ examinan los tweets publicados hasta el 18 de noviembre, día del cierre de campaña, inclusive. ${ }^{21}$ La tabla 7 presenta las propuestas difundidas a través de esta red social.

Tabla 7: Propuestas sobre la UE en las cuentas en la red social twitter de Rajoy y Rubalcaba

\begin{tabular}{|c|c|c|}
\hline Agente & Categoría & Propuesta(s) \\
\hline Rajoy & $\begin{array}{l}\text { Agricultura y } \\
\text { desarrollo rural }\end{array}$ & $\begin{array}{l}\text { - Nos comprometemos a no apoyar la propuesta de } \\
\text { reforma de la PAC ( } 14 \text { de octubre) }\end{array}$ \\
\hline Rubalcaba & $\begin{array}{l}\text { Agricultura y } \\
\text { desarrollo rural }\end{array}$ & $\begin{array}{l}\text { - Defenderemos una PAC restrictiva ( } 10 \text { de } \\
\text { octubre) } \\
\text { - Rechazo a la reforma de la PAC ( } 14 \text { y } 25 \text { de } \\
\text { octubre, } 16 \text { de noviembre) }\end{array}$ \\
\hline Rubalcaba & $\begin{array}{l}\text { Asuntos económicos } \\
\text { y monetarios y euro }\end{array}$ & $\begin{array}{l}\text { - Bajada de los tipos de interés por parte del Banco } \\
\text { Central Europeo (BCE) (11 de octubre; } 7,9 \text { y } 15 \text { de } \\
\text { noviembre) } \\
\text { - Eurobonos (11 de octubre, } 15 \text { y } 17 \text { de noviembre) } \\
\text { - Política económica común ( } 13 \text { de octubre) } \\
\text { - Fortalecimiento del BCE ( } 26 \text { de octubre) } \\
\text { - Recapitalización de los bancos ( } 28 \text { de octubre) } \\
\text { - Retraso a } 2015 \text { del ajuste del déficit ( } 7 \text { de } \\
\text { noviembre) } \\
\text { - Plan Marshall europeo ( } 7,9 \text { y } 14 \text { de noviembre) }\end{array}$ \\
\hline
\end{tabular}

Fuente: Elaboración propia.

De nuevo observamos cómo, de acuerdo con la teoría de la importancia, ambos partidos desenfatizan los temas de la UE. No obstante, el candidato del PSOE destaca medidas concretas de la categoría Asuntos económicos y monetarios, como una mayor flexibilidad en la aplicación del Pacto de Estabilidad, la mutualización de la deuda, o un plan de inversiones a escala europea. No hay referencias correspondientes a las áreas 1 y 2 de nuestro esquema de clasificación, Proceso de Integración e Instituciones

${ }^{20}$ Como anécdota, el 26 de noviembre de 2011, día en el que recogimos esta información, el candidato popular tenía 143.616 seguidores en esta red social, y el candidato socialista, 83.604.

${ }^{21}$ Como lo que nos interesa en esta investigación es la introducción de asuntos de la UE en la campaña a través de este canal, en el examen de los tweets no tuvimos en cuenta las respuestas a otros usuarios de la red. Si lo hiciésemos estaríamos duplicando información, ya que los equipos de campaña respondieron a los tweets reproduciendo contenidos del programa electoral. 
y Actores, sino únicamente al área 3 Políticas Públicas, y de forma muy parca, como acabamos de ver. Tampoco se produce a través de este canal confrontación directa de medidas cuya adopción correspondería al nivel supranacional.

Sin embargo, los candidatos del PP y el PSOE manifiestan a través de twitter su rechazo a la reforma de la PAC, que durante esta campaña movilizó en España a algunos grupos del sector. La inclusión en este trabajo de esta red social como medio de comunicación distinto al programa nos ha permitido detectar esta reacción del PP y el PSOE; pues, en contra de otras fuerzas políticas, ninguno de estos dos partidos había manifestado su rechazo a la reforma de la PAC en su programa electoral, sino solo desenfatizado este asunto, como hemos subrayado en el apartado anterior.

Al mismo tiempo, también se demuestra la mayor validez de los datos resultantes de la codificación de los programas respecto a los recabados a través de cualquier otro medio; vemos cómo el programa es efectivamente el texto más revelador de la estrategia de los partidos.

Volviendo a la red social twitter, más allá de las propuestas programáticas, otra información política canalizada a través de la cuenta de M. Rajoy durante la campaña electoral de 2011 fue la siguiente. El día 29 de octubre, se difundió el mensaje: "No quiero estar en Europa en el pelotón de los torpes, quiero que España esté con los mejores". En el mismo sentido, sobre el cara a cara con Rubalcaba, se twitteó la frase: "España es el $4^{\circ}$ país de la zona euro y debe tener un papel más importante del que está teniendo ahora". El 14 de noviembre, se facilitó el enlace a un artículo publicado en la revista Política Exterior "Mi visión de Europa y España en el mundo". Del mismo modo, a través de la cuenta del candidato A. P. Rubalcaba se difundió el mensaje "la solución a la crisis está en Europa",22 y se defendió puntualmente la gestión del Gobierno socialista anterior, del que había formado parte el propio candidato. ${ }^{23}$

En definitiva, empleando no solo los programas sino también otros canales de comunicación como el debate televisado entre los candidatos a la Presidencia del Gobierno del PP y del PSOE y sus respectivas cuentas en la red social twitter, podemos concluir que la estrategia de los partidos españoles en las elecciones generales de 2011en relación a los asuntos de la UE se ha limitado a desenfatizarlos. Singularmente, los partidos con opciones de gobierno, PP y PSOE, han evitado incluir propuestas claras,

${ }^{22}$ El día 9 de octubre se escribe: "Reclamamos unidad a Europa para ser más fuertes, para generar empleo, tenemos que unirnos todos a todos los niveles"/con motivo de la visita del candidato a Estrasburgo, el 25 de octubre, se twittea: "Hoy Rubalcaba visita el Parlamento europeo en Estrasburgo y se reúne con la alianza progresista de socialistas y demócratas" o "Europa puede continuar convocando una reunión para autoconvocarse para otra o podemos avanzar con decisión, afrontando los problemas"; el día 9 de noviembre se dice: "Si algo hemos aprendido en la UE de esta crisis es que o salimos juntos o lo vamos a pasar muy mal".

23 "El ministro de Fomento José Blanco ha conseguido incluir en las Redes Transeuropeas de Transporte los cinco corredores españoles" (19 de octubre)/“Es evidente que las actuaciones del Gobierno español en 2010 nos han sacado del foco de tensión financiera (Grecia, Portugal, Irlanda, Italia)" (14 de noviembre). 
salvo el PSOE en materias muy puntuales como la fiscalidad o la unión monetaria, y la confrontación directa sobre temas de la Unión.

\section{Conclusiones}

Este artículo, empleando datos del Manifesto Project, ha examinado la importancia de la UE como asunto en las elecciones generales españolas desde la adhesión de este país a la CE en 1986. También, ha analizado la diferenciación de la oferta partidaria sobre temas de la Unión en los comicios de 2011, empleado un esquema de clasificación propio. Para ello, se codificaron las propuestas relativas a los distintos asuntos de competencia o interés supranacional transmitidas a través de los programas de los partidos que obtuvieron representación en esta elección, el único cara a cara televisado y los tweets de los candidatos del PP y del PSOE a la Presidencia del Gobierno.

Los datos confirman las expectativas derivadas de la teoría de la importancia, conforme a las cuales las fuerzas políticas españolas han optado simplemente por desenfatizar los asuntos de la Unión en las elecciones generales. Más allá de la poca importancia de la UE como asunto en la competición electoral a lo largo de los 30 años de integración de España en la CE/UE, esta variable desciende incluso desde mediados de los años noventa del siglo pasado, al mismo tiempo que avanza el proceso de integración europea. Las fuerzas políticas españolas se han mostrado impermeables incluso a los grandes hitos de la construcción europea. Su preocupación por la Unión, lejos de aumentar, cae durante el lanzamiento de la unión monetaria y el debate sobre el fallido Tratado por el que se establece una Constitución para Europa, entre 1996 y 2004.

En definitiva, los partidos españoles no prestan más atención a los asuntos de la Unión conforme aumenta el número de decisiones que se adoptan en el nivel supranacional, o al menos ante decisiones de la Unión especialmente transcendente para el conjunto de Europa o individualmente para España. Al contrario, se ocupan de los temas de la UE cada vez en menor medida, incluso en las elecciones generales de 2011, singularmente condicionadas por la gestión europea de la crisis.

Hemos señalado cómo la tendencia a la desenfatización de la UE en la competición electoral en este país se aparta de la evolución de la importancia de este tema en otros Estados miembros como Francia, Alemania, Italia, o incluso Portugal más recientemente. Poniendo el foco en los años de la Gran Recesión, la evolución de la importancia de la Unión en la competición electoral en España es similar a la griega o la británica. En cambio, en Francia, Italia o Portugal ha aumentado la atención a la UE. Mientras que los partidos españoles se mantienen ajenos a la agenda política europea, en otros Estados sí se detecta relación entre factores europeos e importancia y posiciones partidarias sobre la UE. Por ejemplo, en el período de lanzamiento del euro y del debate sobre el Tratado por el que se establece una Constitución para Europa crecen las referencias a la UE de los partidos parlamentarios franceses, británicos, alemanes o griegos. Cierto es que la competición electoral en Italia y Portugal tampoco se ve afectada por el euro o el debate constitucional; no obstante, los datos españoles son más llamativos, porque, hasta el año 1996, la atención a la UE por parte de las fuerzas políticas del país, aun siendo 
baja, era alta en perspectiva comparada. Asimismo, en los últimos años, la evolución de la importancia de la UE en la competición partidaria en España contrasta también con las variaciones en las actitudes hacia la UE de los ciudadanos del país. No podemos desconocer que, entre 2007 y 2012, España fue el campeón de la pérdida de apoyo a la Unión, de 45 puntos, del $65 \%$ al $20 \%$.

Por otra parte, esta investigación confirma que apenas existe confrontación directa de propuestas acerca de los distintos asuntos de la Unión en las elecciones generales de 2011, sobre todo entre los partidos que han gobernado el país, PP y PSOE. Hemos dado cuenta de la existencia de cierta diferenciación en las ofertas partidarias sobre asuntos de la UE; pero, estas diferencias son menos significativas que la ausencia de diálogo entre propuestas. Las fuerzas políticas españolas, y muy destacadamente el PP y el PSOE, han optado por realizar pocas y vagas referencias a la casi totalidad de los asuntos de la Unión. Así, resulta particularmente próxima la oferta de los dos partidos con opciones de encabezar el Gobierno de España.

Lo que ya sabíamos, pero recordamos, porque con el paso del tiempo ha ganado relevancia, es que la falta de atención a la UE como tema así como a los distintos asuntos de la Unión en la competición electoral en este país dificulta la apertura de un debate público nacional sobre la UE, en el que puedan conformarse y confrontarse posiciones diferenciadas, y emerger una nueva identidad democrática europea más crítica e informada.

En el futuro, convendría examinar los efectos de la ausencia de confrontación partidaria sobre asuntos de la Unión en España sobre la influencia de este país en determinadas decisiones de la UE. También, analizar la asociación entre factores europeos e importancia y posiciones partidarias de las fuerzas políticas estatales que forman parte de un mismo partido a escala europea, explicando las similitudes y diferencias entre partidos nacionales. Incluso, estudiar la convergencia/divergencia entre preferencias de los ciudadanos y de los partidos y sus vínculos con la satisfacción con el funcionamiento de la democracia en los distintos Estados miembros.

\section{Bibliografía}

Aldecoa, F. (coord.) (1994): Elecciones 94: un Parlamento para una legislatura constituyente en la Unión Europea (1994-1999), Madrid, Tecnos.

Alonso, S. (2013): "La fractura democrática en la UE: ¿encaminados hacia la tormenta perfecta?", Agenda Pública, 21/07.

Alonso, S., B. Gómez y L. Cabeza (2013): "Measuring Centre-Periphery Preferences: The Regional Manifestos Project", Regional \& Federal Studies, 23 (2), pp. 189-2, http://dx.doi.org/10.1080/13597566.2012.754351.

Alonso, S., A. Volkens y B. Gómez (2012): Análisis de contenido de textos políticos. Un enfoque cuantitativo, Madrid, CIS. Centro de Investigaciones Sociológicas (Colección Cuadernos Metodológicos, 47).

Álvarez-Miranda, B. (1994): "Integración europea y sistemas de partidos en el sur de Europa: despolarización y convergencia", Revista de Estudios Políticos, 85 (julioseptiembre), pp. 143-167. 
(1996): El sur de Europa y la adhesión a la Comunidad: los debates políticos, Madrid, CIS.

Anduiza, E. y M. Méndez (2001): "Elecciones y comportamiento electoral, 1977-2000", en M. Alcántara y A. Martínez (eds.): Política y gobierno en España, Valencia, Tirant lo Blanch.

Anduiza, E. et al. (2010): "Los usos políticos de Internet en España", Reis. Revista Española de Investigaciones Sociológicas, 129, pp. 133-146.

Aylott, N., L. Morales y L. Ramiro (2007): "Some things change, a lot stays the same", en T. Poguntke et al. (eds.): The Europeanization of National Political Parties, Londres, Routledge.

Barbé, E. (1999): La política europea de España, Barcelona, Ariel. (2003): “The Spanish Presidency: Catalysing a New Axis in the EU?", Journal of Common Market Studies, 41, pp. 45-88, doi: 10.1111/1468-5965.41.s1.4. (ed.) (2010): Entre la irrelevancia internacional y el aprendizaje institucional: la presidencia española de la Unión Europea (2010), Bellaterra, IUEE.

Barreiro, B. e I. Sánchez-Cuenca (2001): "La europeización de la opinión pública española", en C. Closa (ed.): La europeización del sistema político español, Madrid, Istmo, pp. 27-51.

Beneyto, J.M. (1999): Tragedia y Razón. Europa en el pensamiento español del siglo $X X$, Madrid, Taurus.

Braun, D., S. Mikhaylov, H. Schmitt (2010): European Parliament Election Study 2009, Manifesto Study. GESIS Data Archive, Colonia. ZA5057 Versión del archivo de datos 1.0.0, doi:10.4232/1.10204.

Budge, I. (1982): "Electoral volatility: Issue effects and basic change in 23 post-war democracies", Electoral Studies, 1 (2), pp. 147-168, http://dx.doi.org/10.1016/0261-3794(82)90001-4.

(2001): "Theory and Measurement of Party Policy Positions", en I. Budge et al., Mapping Policy Preferences. Estimates for Parties, Electors, and Governments 1945-1998, Oxford: Oxford University Press.

Budge, I. y D. Farlie (1983): Explaining and Predicting Elections: Issue Effects and Party Strategies in Twenty-Three Democracies, Londres, Allen \& Unwin.

Budge, I., D. Robertson y D.J. Hearl (1987) (eds.): Ideology, Strategy and Party Change: Spatial Analysis of Post-War Election Programmes in 19 Democracies, Cambridge, Cambridge University Press.

Carter, E., K.R. Luther y T. Poguntke (2007): "European integration and internal party dynamics", en T. Poguntke et al. (eds.), The Europeanization of National Political Parties, Londres, Routledge.

Closa, C. (ed.) (2001): La europeización del sistema político español, Madrid, Istmo. (2004): "The Formation of Domestic Preferences on the EU Constitution in Spain", Comparative European Politics, 2, pp. 320-338, http://dx.doi.org/10.1057/palgrave.cep.6110041.

(2014) "Los cambios institucionales en la gobernanza macroeconómica y fiscal de la UE: hacia una mutación constitucional europea", Revista de Estudios Políticos, 165, pp. 65-94. 
Cordero García, G. e I. Martín Cortés (2011): ¿Quiénes son y cómo votan los españoles de izquierdas?, Madrid, Los Libros de la Catarata.

Díaz Medrano, J. (1995): La opinión pública española y la integración europea: 1994, Madrid, CIS.

(2003): Framing Europe: Attitudes to European integration in Germany, Spain, and the United Kingdom, Princeton, Princeton University Press.

(2007): "La opinión pública Española y la integración europea (1986-2006)", en F. Morata y G. Mateo (eds.): España en Europa, Europa en España (1986-2006), Barcelona, CIDOB, pp. 205-213.

Díaz Medrano, J. y P. Gutiérrez (2001): "Nested identities: national and European identity in Spain", Ethnic and Racial Studies, 24 (5), pp. 753-778, doi: $10.1080 / 01419870120063963$.

Dolezal, M. et al. (2014): "How parties compete for votes: A test of saliency theory", European Journal of Political Research, 53, pp. 57-76 http://dx.doi.org/10.1111/1475-6765.12017.

Dows, A. (1973) [1957]: Teoría económica de la democracia, Madrid, Aguilar.

Euractiv.es (2010): "España preside por cuarta vez la Unión Europea". Disponible: $22 / 10 / 2015$.

Ezrow, L. y G. Xezonakis (2011): “Citizen Satisfaction with Democracy and Parties' Policy Offerings”, Comparative Political Studies, 44 (9), pp. 1152-1178, http://dx.doi.org/10.1177/0010414011405461.

Fernández-Albertos, J. (2012): Democracia intervenida. Politicas económicas en la gran recesión, Madrid, Catarata.

Fernández Muñoz, J.J. (2006): Las elecciones al Parlamento europeo. Un análisis de sociología electoral (1979-2004), Madrid, Tecnos.

Fernández Pasarín, M. (2007): "Las presidencias españolas del Consejo de la Unión Europea", en F. Morata y G. Mateo (eds.): España en Europa, Europa en España (1986-2006), Barcelona, CIDOB, pp. 97-119.

Graziano, P. y M.P. Vink (eds.) (2007): Europeanization: new research agendas, Palgrave, Houndmills.

Héritier, A. et. al. (2001): Differential Europe. The European Union Impact on National Policymaking, Rowman and Littlefield, Lanham.

Hix, S. y K. Goetz (2000): "Introduction: European Integration and National Political Systems", West European Politics, 23, pp. 1-26, http://dx.doi.org/10.1080/01402380008425398.

Klingemann, H.-D. et al. (2006): Mapping Policy Preferences II. Estimates for Parties, Electors, and Governments in Eastern Europe, the European Union and the OECD, 1990-2003, Oxford, Oxford University Press.

Krippendorff, K. (2004): Content Analysis. An Introduction to its Methodology, Thousand Oaks, Londres y Nueva Dehli, Sage, $2^{\circ}$ edición.

Jurado, I. (2013): “España, del europeísmo al ¿euroescepticismo?", Piedras de Papel, 10/01.

Ladrech, R. (2002): "Europeanization and Political parties: Towards a Framework for Analysis", Party Politics, 8, pp. 389-403,

http://dx.doi.org/10.1177/1354068802008004002. 
(2007): "Europeanization and national party organization. Limited but appropriate adaptation?", en T. Poguntke et al. (eds.): The Europeanization of National Political Parties, Londres, Routledge.

Llamazares, I., M. Gómez-Reino y L. Ramiro-Fernández (2008): "Euroscepticism and Political Parties in Spain", en P. Taggart y A. Szczerbiak (eds.): Opposing Europe? The Comparative Party Politics of Euroscepticism: Volume I: Case Studies and Country Surveys, Oxford, Oxford University Press.

Llamazares, I. y R, Sandell (2001): "Preferencias partidísticas, clivajes políticos y orientaciones hacia la ciudadanía europea en España", en C. Closa (ed.): La europeización del sistema político español, Madrid, Istmo, pp. 107-123.

López Garrido, D. (2010) "Retos y desafíos de la Presidencia española del Consejo de la Unión Europea”, en A. Sorroza Blanco (coord.): Presidencia española de 2010. Retos en una nueva Unión Europea, Madrid, Instituto de Estudios EuropeosUniversidad CEU San Pablo, Fundación Alternativas y Fundación Real Instituto Elcano, pp. 19-23.

Mair, P. (2000): "The Limited Impact of Europe on National Party Systems", West European Politics, 23, pp. 27-51, http://dx.doi.org/10.1080/01402380008425399.

(2007): "Political Parties and Party Systems", en P. Graziano y M.P. Vink (eds.) Europeanization: new research agendas, Palgrave, Houndmills.

Martín, I. e I. Urquizo-Sancho (2012): "The 2011 General Election in Spain: The Collapse of the Socialist Party", South European Society and Politics, 17 (29), pp. 347-363, http://dx.doi.org/10.1080/13608746.2012.708983.

Martínez i Coma, F. (2008): ¿Por qué importan las campañas electorales?, Madrid, Centro de Investigaciones Sociológicas (Colección "Monografías", 260).

Martínez, A. y M. Méndez (eds.) (2000): Las elecciones al Parlamento Europeo, 1999, Valencia, Tirant lo Blanch.

Menéndez, I. (2012): "Integración monetaria y rendición de cuentas en Europa, 19881994”, Reis. Revista Española de Investigaciones Sociológicas, 137 (1), pp. 99-120.

Molina, I. (2001): "La adaptación a la UE del poder ejecutivo español", en C. Closa (ed.): La europeización del sistema político español, Madrid, Istmo, pp. 160-196.

Morata, F. (1996): "Fundamentals of Spain in EU Affairs", en W. Wessels (ed.): The European Union and Member States. Towards Institutional Fusion?, Manchester, Manchester University Press, pp. 134-154.

(1999): La Unión Europea. Procesos, actores y políticas, Barcelona, Ariel.

Morata, F. y A. Fernández (2003): “The Spanish Presidencies of 1989, 1995 and 2002: From Commitment to Reluctance towards the EU", en O. Elgström (ed.): European Union Council Presidencies: A Comparative Perspective, Londres, Routlegde, pp. 173-190.

Moreno, L. (2013): La Europa asocial, Barcelona, Península. (2014): Una Europa sin Estados. Unión política en el (des)orden global, Madrid, Catarata. 
Nanou, K. y H. Dorussen (2013): "European integration and electoral democracy: How the European Union constraints party competition in the Member States", European Journal of Political Research, 52, pp. 71-93, http://dx.doi.org/10.1111/j.1475-6765.2012.02063.x.

Piedrafita, S. (2013): "Los ciudadanos ante las elecciones europeas. Retos actuales y propuestas de reforma", Panorama social, 17, pp. 133-148.

(2014): "The Spanish Parliament and EU Affairs in the Post Lisbon Treaty Era: All Change?", The Journal of Legislative Studies, 20 (4), pp. 451-472, http://dx.doi.org/10.1080/13572334.2014.919711.

Quintanilla Navarro, M. (2000): "Los partidos políticos españoles ante el proceso de integración europea", Revista de Estudios Políticos, 108 (abril-junio), pp. 307-323.

Radaelli, C.M. (2006): "Europeanization: solution or problem?", en M. Cini y A.K. Bourne (eds.): European Union Studies, Palgrave Macmillan, Houndmills.

Ramiro, L. y L. Morales (2007): "European Integration and Spanish Parties. Elite Empowerment and Spanish Adaptation", en T. Poguntke et al. (eds.): The Europeanization of National Political Parties. Power and Organizational Adaptation, Londres, Routledge.

Rauh, C. (2014): "Communicating supranational governance? The salience of EU affairs in the German Bundestag 1991-2013", European Union Politics, 16 (1), pp. 116-138, doi: 10.1177/1465116514551806.

Raunio, T. (2002): "Why European Integration Increases Leadership Autonomy within Political Parties", Party Politics, 8, pp. 405-22, http://dx.doi.org/10.1177/1354068802008004003. (2007): "Resisting Change: European Integration and National Party Systems", en R. Holzhacker y E. Albaek (eds.): Democratic Governance and European Integration. Linking Societal and State Processes of Democracy, Cheltenham, Edward Elgar.

Rodríguez-Aguilera de Prat, C. (2007) "Elecciones europeas y partidos en España”, en F. Morata y G. Mateo (eds.): España en Europa, Europa en España (1986-2006), Barcelona, CIDOB, pp. 179-204.

(2008): Partidos políticos e integración europea, Barcelona, ICPS.

(2015): El déficit democrático europeo. La respuesta de los partidos en las elecciones de 2014, Madrid, Catarata.

Román Marugán, P. (2001): "Partidos, programas e integración europea. La europeización del sistema de partidos español”, en C. Closa (ed.): La europeización del sistema político español, Madrid, Istmo, pp. 52-67.

Sánchez-Cuenca (1999): "El déficit democrático de la Unión Europea", en I. Llamazares y F. Reinares (eds.): Aspectos políticos y sociales de la integración europea, Valencia, Tirant lo Blanch.

(2014): La impotencia democrática. Sobre la crisis política de España, Madrid, Catarata.

Sánchez-Cuenca, I. y E. Dinas (2012): "Introduction: Voters and Parties in the Spanish Political Space", South European Society and Politics, 17 (3), pp. 365-374, http://dx.doi.org/10.1080/13608746.2012.701889. 
Sorroza Blanco, A. e I. Molina (2010): "La presidencia española de 2010 como primera experiencia post-Lisboa", en A. Sorroza Blanco (coord.): Presidencia española de 2010. Retos en una nueva Unión Europea, Madrid, Instituto de Estudios EuropeosUniversidad CEU San Pablo, Fundación Alternativas y Fundación Real Instituto Elcano, pp. 165-176.

Stevens, D. (2013): "Issue Evolution in Britain: The Debate on European Union Integration, 1964-2010”, European Journal of Political Research, 52 (4), 536-557, doi: $10.1111 / 1475-6765.12004$.

Torcal, M. y J. Font (2012): "Las elecciones europeas de 2009. Un marco de discusión", en M. Torcal y J. Font (eds.): Elecciones europeas 2009, Madrid, CIS, pp. 11-38.

Torcal, M. y J. Muñoz (2012): "Actitudes hacia la Unión Europea y elecciones al Parlamento Europeo", en M. Torcal y J. Font (eds.), Elecciones europeas 2009, Madrid, CIS, pp. 197-225.

Torreblanca, I. (2014): ¿Quién gobierna en Europa? Reconstruir la democracia, recuperar a la ciudadanía, Madrid, Catarata.

Urquizu, I. (2012): La crisis de la socialdemocracia: ¿qué crisis?, Madrid, Catarata.

Vink, M.P. y P. Graziano (2007): "Introduction: Challenges of a New Research Agenda", en P. Graziano y M.P. Vink, Europeanization. New Research Agendas, Houndmills, Palgrave Macmillan.

Volkens, A. (2002): Manifesto Coding Instructions (2 ${ }^{\mathrm{a}}$ ed. rev.), Discussion Paper FS III 02-201, Berlín, WZB.

Volkens, A. et al. (2012): The Manifesto Data Collection. MARPOR (MRG/CMP/ MARPOR), Berlín, WZB.

Volkens, A. et al. (2013): Mapping Policy Preferences from Texts III, Statistical Solutions for Manifesto Analysts, Oxford, Oxford University Press.

Volkens, A., C. Ares y N. Merz (2014): "Range, Scope, and Extent of MARPOR Data Usage and Validation: A Survey of Publications in High-Impact Journals", paper presentado en el Congreso "Mapping Policy Preferences from Texts", panel 1 "Usage and Validity of the Manifesto Estimates", 15/05. Berlín: WZB.

Volkens, A. et al. (2015a): The Manifesto Data Collection. Manifesto Project (MRG/ CMP/MARPOR). Versión 2015a, Berlín, WZB.

Volkens, A., C. Ares, R. Bratanova y L. Kaftan (2015b): Scope, Range, and Extent of Manifesto Project Data Usage: A Survey of Publications in Eight High-Impact Journals. Handbook for Data Users and Coders. Berlín, WZB.

Volkens, A., C. Ares, R. Bratanova y L. Kaftan (2015c): "Scope, Range, and Extent of Manifesto Project Data Usage: a New Research Tool for Manifesto Project Database's Users“, Revista de Investigaciones Politicas y Sociológicas, 14 (2), pp. 215-232. 


\section{Apéndice}

Tabla 8: Esquema de clasificación de propuestas sobre asuntos de la UE²4

\begin{tabular}{|l|l|}
\hline Áreas & Categorías \\
\hline $\begin{array}{l}\text { Área 1: } \\
\text { PROCESO DE } \\
\text { INTEGRACIÓN }\end{array}$ & $\begin{array}{l}\text { 101 Ampliación (adhesión de nuevos Estados) } \\
102 \text { Profundización ("más Europa") } \\
103 \text { Democratización (propuestas dirigidas a mejorar la } \\
\text { legitimidad democrática de la UE) }\end{array}$ \\
\hline & \\
Área 2: & $\begin{array}{l}\text { 201 Gobierno multinivel } \\
\text { 202 Instituciones y órganos de la UE } \\
\text { 203 Partidos políticos a escala europea } \\
\text { ACTORES } \\
\text { 204 Grupos de interés } \\
\text { 205 Legitimidad (tanto de origen como de resultados, de la UE } \\
\text { en su configuración actual) }\end{array}$ \\
& \\
\hline
\end{tabular}

${ }^{24}$ Nótese que la distribución de competencias entre la UE y los Estados miembros es variable entre materias y en el tiempo. En el momento actual, las decisiones sobre el proceso de integración siguen siendo intergubernamentales, lo mismo que los acuerdos en las categorías 312 o 313, sobre Política Exterior o de Seguridad y Defensa. La extensión de la acción de la UE es mayor en materias como comercio (303), agricultura (307), pesca (308), mercado interior (302), monetaria en los países de la zona euro (304), y más limitada en asuntos sociales (306) o educación (315). En la mayor parte de las áreas de políticas, la competencia es compartida entre la UE y los Estados; por ejemplo, política regional (310), de energía (318), transportes (319) o medioambiente (309). 


\begin{tabular}{|c|c|}
\hline Áreas & Categorías \\
\hline $\begin{array}{l}\text { Área 3: } \\
\text { POLÍTICAS } \\
\text { PÚBLICAS }\end{array}$ & $\begin{array}{l}301 \text { Programación financiera y presupuesto } \\
302 \text { Mercado interior y competencia } \\
303 \text { Comercio } \\
304 \text { Asuntos económicos y monetarios y euro } \\
305 \text { Fiscalidad } \\
\text { 306 Asuntos sociales e inclusión } \\
\text { 307 Agricultura y desarrollo rural } \\
\text { 308 Asuntos marítimos y pesca } \\
\text { 309 Medioambiente } \\
\text { 310 Política regional } \\
\text { 311 Espacio de Libertad, Seguridad y Justicia } \\
312 \text { Política Exterior y Política de Vecindad } \\
\text { 313 Política de Seguridad y Defensa } \\
\text { 314 Cooperación internacional, ayuda humanitaria y respuesta a } \\
\text { las crisis } \\
\text { 315 Educación y juventud } \\
\text { 316 Investigación e innovación } \\
\text { 317 Agenda digital } \\
318 \text { Energía } \\
\text { 319 Transportes } \\
320 \text { Industria } \\
\text { 321 Otras políticas o cuestiones transversales de políticas } \\
\text { públicas }\end{array}$ \\
\hline
\end{tabular}

Fuente: Elaboración propia.

Tabla 9: Frecuencias propuestas programáticas sobre asuntos de la UE en 2011 (partidos con representación parlamentaria)

\begin{tabular}{|l|r|r|}
\hline Categorías & $\begin{array}{c}\text { Frecuencia } \\
\text { absoluta }\end{array}$ & $\begin{array}{c}\text { Frecuencia } \\
\text { relativa }\end{array}$ \\
\hline Ampliación & 5 & $2,3 \%$ \\
\hline Profundización & 6 & $2,8 \%$ \\
\hline Democratización & 4 & $1,8 \%$ \\
\hline Gobierno multinivel & 8 & $3,7 \%$ \\
\hline Instituciones y órganos de la UE & 2 & $0,9 \%$ \\
\hline
\end{tabular}




\begin{tabular}{|c|c|c|}
\hline Categorías & $\begin{array}{l}\text { Frecuencia } \\
\text { absoluta }\end{array}$ & $\begin{array}{l}\text { Frecuencia } \\
\text { relativa }\end{array}$ \\
\hline Partidos políticos a escala europea & 1 & $0,5 \%$ \\
\hline Legitimidad & 3 & $1,4 \%$ \\
\hline Programación financiera y presupuesto & 9 & $4,1 \%$ \\
\hline Mercado interior y competencia & 4 & $1,8 \%$ \\
\hline Comercio & 2 & $0,9 \%$ \\
\hline Asuntos económicos y monetarios y euro & 45 & $20,7 \%$ \\
\hline Fiscalidad & 18 & $8,3 \%$ \\
\hline Asuntos sociales e inclusión & 1 & $0,5 \%$ \\
\hline Agricultura y desarrollo rural & 23 & $10,6 \%$ \\
\hline Asuntos marítimos y pesca & 7 & $3,2 \%$ \\
\hline Medioambiente & 1 & $0,5 \%$ \\
\hline Política regional & 2 & $0,9 \%$ \\
\hline Espacio de Libertad, Seguridad y Justicia & 22 & $10,1 \%$ \\
\hline Política Exterior y Política de Vecindad & 19 & $8,8 \%$ \\
\hline Política de Seguridad y Defensa & 3 & $1,4 \%$ \\
\hline $\begin{array}{l}\text { Cooperación internacional, ayuda humanitaria } \\
\text { y respuesta a las crisis }\end{array}$ & 6 & $2,8 \%$ \\
\hline Educación y juventud & 8 & $3,7 \%$ \\
\hline Investigación e innovación & 2 & $0,9 \%$ \\
\hline Agenda digital & 3 & $1,4 \%$ \\
\hline Energía & 5 & $2,3 \%$ \\
\hline Transportes & 2 & $0,9 \%$ \\
\hline Industria & 3 & $1,4 \%$ \\
\hline $\begin{array}{l}\text { Otras políticas o cuestiones transversales } \\
\text { de políticas públicas }\end{array}$ & 3 & $1,4 \%$ \\
\hline
\end{tabular}

Fuente: Elaboración propia. 